\title{
Pediatric
RESEARCH
}

\section{Subclinical mastitis occurs frequently in association with dramatic changes in inflammatory/anti-inflammatory breast milk components}

\begin{tabular}{|r|l|}
\hline Journal: & Pediatric Research \\
\hline Manuscript ID & PR-2016-0078.R2 \\
\hline Manuscript Type: & Original research article, translational \\
\hline Complete List of Authors: & $\begin{array}{l}\text { Tuaillon, Edouard } \\
\text { Voljoen, Johanes } \\
\text { Dujols, Pierre } \\
\text { Cambonie, Gilles } \\
\text { Nagot, Nicolas } \\
\text { Bland, Ruth } \\
\text { Badiou, Stéphanie } \\
\text { Newell, Marie-Louise } \\
\text { Van de Perre, Philippe }\end{array}$ \\
\hline Keywords: & Keyword 1 \\
\hline
\end{tabular}


1

2

3

4

5

6

\section{Subclinical mastitis occurs frequently in association with dramatic changes in inflammatory/anti-inflammatory breast milk components}

Running Title: Inflammatory response during SCM

Edouard Tuaillon ${ }^{1,2^{*}}$, Johanes Viljoen ${ }^{1,3,4}$, Pierre Dujols ${ }^{1,5}$, Gilles Cambonie ${ }^{6}$, Pierre-Alain Rubbo $^{1}$, Nicolas Nagot ${ }^{1,5}$, Ruth M Bland ${ }^{3,7}$, Stéphanie Badiou ${ }^{8}$, Marie-Louise Newell, Philippe Van de Perre ${ }^{1,2}$

${ }^{1}$ UMR Inserm U1058, EFS, Université Montpellier 1, Montpellier France

${ }^{2} \mathrm{CHRU}$ de Montpellier, Département de Bactériologie-Virologie, Montpellier, France

${ }^{3}$ Africa Centre for Health and Population Studies, University of KwaZulu-Natal, Durban, South Africa

${ }^{4}$ Department Virology, Faculty of Health Sciences, University of the Witwatersrand, Parktown, South Africa

${ }^{5} \mathrm{CHRU}$ de Montpellier, Département d'Information Médicale, Montpellier, France

${ }^{6} \mathrm{CHRU}$ de Montpellier, Département de Néonatologie, Montpellier France

${ }^{7}$ Royal Hospital for Sick Children, Glasgow, UK

${ }^{8}$ Département de Biochimie, CHRU Montpellier, Université de Montpellier, France

${ }^{9}$ Faculty of Medicine, University of Southampton, Southampton, UK 
*correspondence to Edouard Tuaillon: e-tuaillon@chu-monpellier.fr Laboratoire de Virologie, Hôpital Lapeyronie, CHRU de Montpellier 191, Av du Doyen G. Giraud 34295 Montpellier

Tel: 33467338469

Fax: 33467338334

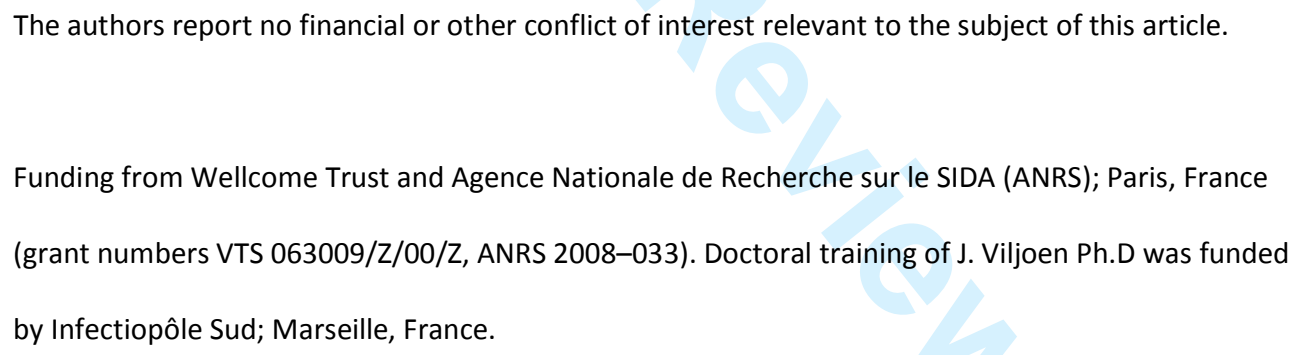




\begin{abstract}
Background: Subclinical mastitis (SCM) is a frequent, but poorly characterized entity that may influence immune development of breastfed infants. Mechanisms driving the emergence of SCM and changes in immunological content of human milk during SCM remains to be explored. In this study, the breast milk environment was to describe during SCM.

Methods: One hundred ten samples of mature breast milk were collected from 44 healthy, HIV negative mothers, included in a large infant feeding intervention cohort (ANRS 1271/Vertical Transmission Study). Immune markers related to inflammatory/anti-inflammatory balances and secreted in response to bacterial exposure were explored in SCM breast milk samples ( $\mathrm{Na} / \mathrm{K}$ ratio >1) and compared to non-SCM controls.

Results: SCM was observed in $23 \%$ of women (95\% Cl: $21-24)$ and associated with higher levels of inflammatory markers ( $\beta 2$ microgobulin, PS100A9, TNF- $\alpha$, IL-6, IL-8, IL-17 and RANTES) and Th1related cytokines (IL-2R, IL-12p40/70, IFN- $\alpha, I F N-\gamma$, CXCL-9, andIP-10). High levels of factors secreted in response to bacteria and lipopolysaccharide (LPS) exposure where observed in SCM breast milk samples (MIP-1 $\alpha$, MIP-1 $\beta$, LPS binding protein, $\alpha$-defensins, and antileukoproteinase 1 ).

Conclusion: SCM is associated with important changes in breast milk microenvironment, with a proinflammatory/Th1-cytokine predominant profile. During SCM, cytokine imbalances in breast milk may have a notable influence on mucosal immune system of the infant early in life.
\end{abstract}




\section{INTRODUCTION}

Epidemiological and biological studies have proven the benefits of breastfeeding for child health. Breastfeeding have short-term and long-term health consequences for the child [1]. Breast milk down-regulates gut inflammation and promotes gut adaptation in the neonatal period when the newborn is suddenly exposed to antigens from colonizing commensal bacteria. According to clinical and experimental observations, human milk should not only be viewed as a source of nutrition and passive protection during a period of immunological immaturity, but also as a biological fluid able to modulate the immunological development of the recipient infant [2].

To date, immune factors and cytokines contained in human breast milk remain only partially characterized. High levels of interleukin-1 beta (IL-1ß), interleukin-6 (IL-6), tumor necrosis factoralpha (TNF- $\alpha$ ) and IFN- $\gamma$ were found in breast milk samples from healthy lactating mothers (3). Cytokines belonging to the CXC and CC chemokine families are also measurable in breast milk. These small chemotactic cytokines are mediators of inflammation able to attract and activate leukocytes. The presence of monocyte chemotactic protein (MCP-1), RANTES (regulated upon activation, normal T-cell expressed and secreted), and macrophage inflammatory protein 1 alpha (MIP-1 $\alpha$ ) of the CC chemokine family, as well as interleukin-8 (IL-8) of the CXC chemokine family, have all been demonstrated in breast milk [2]. These cytokines have been shown to be expressed (mRNA) and secreted by both mammary epithelial cells and breast milk leukocytes. Granulocyte-macrophage colony-stimulating factor (GM-CSF) was also identified in human breast milk [3]. In addition to these pro-inflammatory and Th1-related cytokines, interleukin-10 (IL-10), a key immunoregulatory and anti-inflammatory cytokine, has been measured in significant concentrations in lactoserum and the lipid layer of breast milk [4]. Erythropoietin (EPO) is another stimulating factor found in breast milk[5], and HIV transmission through breastfeeding is inversely related to the concentration of EPO in breast milk [6]. Alongside the well-known function of EPO to stimulate red blood cell production, 
EPO might promote the integrity of the mammary and gut epithelium through cytoprotective properties and limitation of inflammation [7].

Mastitis, a local infection associated with inflammation and increased mammary epithelial permeability, induces considerable changes in the immunological contents of milk in animals. An elevated sodium/potassium $(\mathrm{Na} / \mathrm{K})$ ratio in breast milk has been demonstrated as an indicator of mastitis. This elevated ratio, accompanied by an increased concentration of IL-8, is also frequently seen in asymptomatic lactating women, thus characterizing an episode of subclinical mastitis (SCM), which is a recently defined and poorly understood entity $[8,9]$. Studies investigating HIV transmission by breastfeeding demonstrated a high prevalence of SCM in both HIV-infected and uninfected lactating women, ranging from $10 \%$ to $45 \%$ [10]. SCM is associated with increased HIV load in breast milk of infected women and may be associated with increased risk of mother-to-child transmission of HIV [11]. Almost a quarter of breast milk samples collected during the first month of lactation, and more than $10 \%$ thereafter, present with biological features of SCM $[12,13]$. SCM may well precede symptomatic mastitis but the low frequency of clinical mastitis compared to episodes of SCM indicates that in the majority of cases the immune response is able to avoid significant breakthrough infection during lactation. The consequences of SCM on the immunological content of breast milk and the mechanisms driving the emergence of SCM need to be established. We propose that SCM induces dramatic changes in breast milk immune contents. Culture-dependent research and microbiome approaches have shown that normal human milk contains a wide range of commensal bacteria contributing to neonatal gut microbiota and potentially preventing pathogen growth [14]. Exposure to pathogen microorganisms may trigger the immunological changes seen during SCM. However, this assumption is challenged by the fact that conditions such as cessation of breastfeeding, micronutrient deficiencies, milk stasis (engorgement) or systemic infections may also be responsible for a raised $\mathrm{Na} / \mathrm{K}$ ratio [15-17].
Field Code Changed

Field Code Changed

Field Code Changed

Field Code Changed

Field Code Changed

Field Code Changed

Field Code Changed 


\begin{abstract}
The aim of our study was to describe the breast milk environment during SCM in healthy mothers: the frequency of the phenomenon and changes in the Th1 versus Th2 related factors and inflammatory versus anti-inflammatory equilibriums that accompany it. This study was nested within a large mother-to-child HIV transmission study, but was focused on HIV-uninfected women and their infants only [18]. We observed that some immunological parameters contained in breast milk are robust markers of SCM. Changes in Th1/Th2 and inflammatory/anti-inflammatory balance during SCM may influence gut homeostasis in newborns. In view of the potential association between bacterial exposure and the onset of SCM, we tested immunological parameters associated with innate responses to LPS exposure.
\end{abstract}

\title{
RESULTS
}

\section{Frequency of unilateral and bilateral SCM during lactation}

The median $\mathrm{Na}+$ and $\mathrm{K}+$ concentrations were 10 (IQR 9-11.8) and 12.8 (IQR 11.5-14.3) mmol/L respectively $(\mathrm{n}=110)$. The median $\mathrm{Na} / \mathrm{K}$ ratio was 0.77 (IQR 0.69-0.92). An episode of SCM as defined by a $\mathrm{Na} / \mathrm{K}$ ratio of $>1.0$ was observed in 10 of the 44 women ( $23 \% ; 95 \% \mathrm{Cl}: 21-24 \%)$, and 18 of 110 samples (16\%; 95\% Cl: 16\%-17\%). This abnormality in mammary epithelial permeability was bilateral in 5 cases, and unilateral in 8 cases, with one woman having one episode of bilateral and one episode of unilateral SCM, and another woman having three episodes of unilateral SCM.

\section{Assessment of bioactive components in human milk.}

Of the 25 cytokines analyzed by multiplex microbeads assay, most were measurable in breast milk with concentrations within the range of quantification of the assay. However, TNF- $\alpha$ was quantifiable only in a minor proportion of samples $(20 / 113 ; 18 \%)$, and IFN- $\alpha$ in $32 / 113$ samples (28\%). IL-1 $\beta$ were below the lower limit of detection in 16/113 (14\%) samples, and Eotaxin in 19/113 (17\%) of samples tested. By comparison with references values observed in blood, breast milk samples from the 


\section{Immunological components increased during SCM}

SCM induced numerous changes in immunological content of breast milk (Table 1). Most factors associated with inflammation ( $\beta 2$ microgobulin, PS100A9, TNF- $\alpha$, IL-6, IL-8, IL-17 and RANTES) were significantly increased in SCM samples as compared to control samples after adjusting for multiple comparisons. Of the cytokines involved in the Th1 response, 6 out of 8 were also significantly increased in the SCM group (IL-2R, IL-12p40/70, IFN- $\gamma$, IFN- $\alpha$, monokine induced by gamma interferon (MIG or CXCL-9), and IP-10 ( $p<0.001)$. Regarding Th2-related cytokines, only IL-4 was found in significantly higher concentrations in samples from the SCM group than in controls ( $p<0.001)$. Lactoferrin, IL-10 and EPO, three factors associated with anti-inflammatory properties of breast milk, were not significantly increased during SCM. The median level of IL-1RA was 3-fold higher in the SCM group than in controls $(p<0.001)$.

In 7 women with unilateral SCM, within-woman comparison of breast milk showed that markers of inflammation IL-8, IP-10, IFN- $\gamma$ and IL-12p40/70 were generally more elevated in the side affected by SCM (Figure 1). The differences were significant for IL-12p40/70 (median 58.1 pg/mL, IQR 41.7-87.6, $\mathrm{p}=0.046)$ and IL-8 (median $488.6 \mathrm{pg} / \mathrm{mL}$, IQR 225.7-1324.1, $\mathrm{p}=0.031)$.

\section{Alterations in the Th1/Th2 and pro-/anti-inflammatory balances during SCM}

The relative concentrations of Th1/Th2 and pro-/anti-inflammatory related markers were analyzed to describe changes of breast milk environment during SCM. The ratio of pro- versus anti-inflammatory related factors was increased during SCM although the increase seen in IL-1RA and lactoferrin 
partially compensated for the high concentration of pro-inflammatory related cytokines (Figure 2, panel A).

Changes in the ratio of Th1/Th2-related cytokines were also observed in the SCM group as compared to controls with a predominant elevation of cytokines that belong to the Th1-type immune response (Figure 2, panel B).

\begin{abstract}
A Th1 and pro-inflammatory signature can be used to identify SCM
Additionally, we explored the possibility to appropriately identify SCM with factors related to proinflammatory (IL-8 and PS100A9) and Th1 (IFN- $\nu$ and IP-10) responses in breast milk using receiver operating characteristic (ROC curves). The greatest area under curve was obtained with IP-10 (AUC 0.86) and IFN- $\gamma$ (AUC 0.85). IL-8 and PS100A9 offered also good discriminatory capacity between SCM and control samples (AUC 0.78 and 0.77 , respectively) (Figure 3 ). For example, the sensitivity and specificity were $70 \%$ and $94 \%$ respectively with a cut off value of $2551 \mathrm{pg} / \mathrm{mL}$ for IP-10. Using a cut off value of $1092 \mathrm{pg} / \mathrm{mL}$ for IP-10, the sensitivity and specificity were 94\% and 64\% respectively. Lower performances were obtained with the other factors found in significantly higher concentrations during SCM by comparison with controls such as IL-12p40/70, IFN- $\alpha$ and IL-17 (data not shown).
\end{abstract}

\title{
Relationship between SCM and immunological factors secreted in response to bacterial exposure
}

A combination of markers secreted in response to LPS and bacterial antigens were tested to demonstrate the association between bacterial exposure and SCM, namely: MIP-1 $\alpha$ and MIP-1 $\beta$, MCP-1, sCD14, LPS binding protein, antileukoproteinase 1 and $\alpha$-defensins.

SCM samples were associated with high concentrations of factors associated with bacterial exposure (Table 2). Levels of factors secreted in response to bacteria and LPS exposure where significantly higher in SCM samples by comparison to normal breast milk, for: MIP-1 $\alpha$, MIP-1 $\beta$, LPS binding 


\section{DISCUSSION}

Breast milk contains numerous immunological factors that play a pivotal role in modulating infant's mucosal immune system as well as susceptibility to pathogens [11]. Some of these highly active factors are found at higher concentrations than in blood $[2,19]$, highlighting the importance of the immunomodulatory functions of breast milk. Consequently, changes in immune responses during SCM may impact on breast milk immunomodulatory functions. In this study we observed that a predominant Th1 and pro-inflammatory signature characterized SCM. Furthermore, some of the human milk immune components had good performance to identify SCM when used as surrogate makers of $\mathrm{Na}+/ \mathrm{K}+$ ratio. Finally, markers of the immune response against LPS were associated with SCM suggesting that bacteria exposure was involved.

A raised $\mathrm{Na}+/ \mathrm{K}+$ ratio that characterizes SCM was found in almost a quarter of mothers, a frequency comparable with observations made in other settings $[12,13]$ despite the intensive efforts made to promote good breastfeeding practices in this clinical study [20].

Although some levels of inflammation had already been suggested in association with SCM, our study demonstrates that a raised $\mathrm{Na}+\mathrm{K}+$ ratio is associated with a full spectrum inflammatory process in 
the mammary gland consisting of higher levels of most of the inflammatory markers (e.g. $\beta 2$ microglobulin, protein S100A9, IL-6, IL-8 and TNF- $\alpha$ ), when compared to normal breast milk samples. A clear inflammatory process was also observed in at least two samples with a $\mathrm{Na}+\mathrm{K}+$ ratio below 1 . Thus, additional parameters such as IP-10, IL-8, or protein S100A9 may be used in combination with the $\mathrm{Na}+\mathrm{K}+$ ratio to better define SCM. Samples were collected from 1 to 16 months after delivery. Whereas cytokine expression decreases during the first month of lactation in transitional breast milk, immune components appear relatively stable in mature breast milk [21].

To our knowledge, this is the first study to show the clear association of protein S100A9 with the immune responses found in human SCM. Protein S100, secreted by mammary epithelial cells and lymphocytes, are found at high concentrations in mature breast milk [22]. In a previous study based on a quantitative proteomic approach we observed an association between protein S100A9 in breast milk and HIV mother to child transmission before 4 month of age [23]. These acidic calcium-binding proteins are involved in brain development of the infant and inflammation. Studies in animal models of mastitis suggest that proteins of the $\mathrm{S} 100$ family may also have anti-bacterial activity [24]. High levels of IL-8 in breast milk have been previously described in SCM [9, 12, 25]. IL-8 is a chemokine produced by macrophages and epithelial cells, both of which are an important fraction of the breast milk cellular composition [11]. IL-8 is a major mediator of the inflammatory response playing a key role in the innate response. Side by side comparison of cytokines levels indicated that SCM is a local event. Breast milk IP-10 and MIG are secreted in response to IFN- $\gamma$. IP-10 is produced by a variety of cells, including monocytes, fibroblasts and endothelial cells, and MIG mainly by lymphocytes. Both chemokines target the CXCR-3 receptor and contribute to the recruitment and activation of T lymphocytes, natural killer cells, and monocytes. As illustrated by the increased levels of Th1 cytokines, a cytotoxic T lymphocyte response is promoted during the course of SCM.

In contrast to high levels of Th1-related cytokines, and except for IL-4, SCM was not associated with significantly higher concentrations of Th2 cytokines (IL-5, IL-10, IL-13) as compared to controls. 


\begin{abstract}
Hence, the cytokine profile in breast milk appeared to be dominated by the Th1 response during
\end{abstract} SCM. Of breast milk anti-inflammatory mediators, SCM was associated with a higher level of IL1-RA but with no significant rise of IL-10, EPO or lactoferrin. The high concentrations of Th1 and proinflammatory-related cytokines may be only partially compensated for by changes in Th2 and antiinflammatory cytokine levels. Relative changes in concentrations of Th1- vs Th2-related cytokines and pro- vs anti-inflammatory factors in breast milk can be viewed as disequilibrium in breast milk immunological components during SCM. In addition, inflammation in breast milk interplays with breast milk fatty acid profile. Hence, we recently observed that IL15, IP10, and $\beta 2$ microglobulin, correlate positively for cis-vaccenic acid, and negatively for eicosatrienoic acid in breast milk collected from HIV infected mothers [26].

Field Code Changed Regarding the pivotal role of breast milk in the maturation of gut and mucosal-associated lymphoid tissue in the newborn, these findings raise the question of the impact of SCM on the infant. Physiologically, it is thought that breast milk provides protective anti-inflammatory factors containing the propensity of the immature human small intestine to respond to commensal colonizing bacteria by an excessive inflammatory response [27]. In preterm infants breast milk limits the incidence of necrotizing enterocolitis [28]. This disease of the immature bowel is probably induced by an inflammatory response. During necrotizing enterocolitisa defect in NF-kB regulation with an excessive production of inflammatory cytokines in responses to the commensal flora is observed [7]. In an animal model colostral whey reduced the IL-8 inflammatory response of fetal human xenografts after an inflammatory stimulus with IL-1 $\beta$ and the luminal expression of TLR-4, which is an important cell receptor of the innate inflammatory response [29]. In vitro EPO and IL-10 used at concentrations found in breast milk are able to negatively control the IL- 8 secretion by a fetal human enterocyte cell line. EPO also reduces the susceptibility to IFN- $\gamma$-induced experimental neonatal necrotizing lesions [7]. Lactoferrin reduces the production of inflammatory cytokines by monocytes by inhibiting

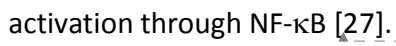


Milk stasis is classically considered as the primary cause of mastitis and may progress to infection [8, 9]. It has been proposed to classify mastitis as mastitis-milk stasis, -infectious, and -noninfectious. This classification is originally based on work performed by Thomsen and colleagues that analyzed leukocyte count and bacteria in milk from breasts with clinical signs of mastitis in the 1980's [30]. Recent studies have shown that subclinical mastitis is much more frequent than clinical mastitis. Inflammation in human milk may be influenced by a large number of causes. Allergy [31] and infection [32] of the mother impact on breast milk inflammation markers. Maternal country of origin [33] and stress may also influence breast milk contents. Studies of Hassiotou F et al. [34], and Riskin A et al. [35], have reported a raise in leukocyte count, antibodies and inflammation markers in mothers' breast milk during active infection in nursing infants, supporting a very dynamic nature of the immune defense provided by breastfeeding in mother-infant dyads.

To investigate bacterial exposure as the main cause of SCM, we explored the relationship between the $\mathrm{Na} / \mathrm{K}$ ratio and anti-microbial factors secreted in response to bacterial antigen exposure. During SCM we observed high levels of mediators related to the innate response to bacteria and LPS including MIP-1 $\alpha$, MIP-1 $\beta$, MCP-1, LBP, SCD14, antileukoproteinase 1 and $\alpha$-defensins. The rise of MIG and IP-10 that have defensin-like functions against bacteria [36] suggest that bacterial exposure is involved in SCM. MIP-1 $\alpha$ and MIP-1 $\beta$ are also secreted by macrophages after stimulation by bacterial toxins [37]. SCD14 is a pattern recognition receptor playing a pivotal role in the recognition of cell activation induced by microbial cell wall components of bacteria. SCD14 is present in high concentrations in human milk where it is a key mediator of innate responses [38]. SCD14 is believed to regulate microbial growth in the neonatal gut and is expressed mainly by macrophages and to a lesser extent by neutrophil granulocytes. SCD14 in human milk is a co-receptor for TLR 4 which detects gramnegative bacteria through LPS fixation and confers LPS-responsiveness to cells that do not express CD14 [39].
Field Code Changed

Field Code Changed
Field Code Changed

Field Code Changed

Field Code Changed

Field Code Changed
Field Code Changed

Field Code Changed 
To our knowledge this is the first report measuring LBP during human SCM. Our findings suggest that LBP is dramatically increased during SCM, and is therefore associated with the innate response mediated by SCD14 in breast milk during SCM. LBP facilitates delivery of endotoxin aggregates to sCD14 to form monomeric endotoxin-sCD14 complexes and subsequent interactions of endotoxinsCD14 with TLR4. However, LBP is present at low concentrations in normal human breast milk [38], leading to a more controlled immune response against bacteria. Indeed, sCD14 can mediate CD14negative cell activation by LPS in the absence of LBP, albeit with slower kinetics [40]. However, we observed a median level of LBP that was 5 -fold higher during SCM by comparison with normal milk, whereas SCD14 was 2 fold higher in the SCM group.

Besides LBP, and by comparison with normal breast milk, SCM is also associated with higher levels of MIP-1 $\alpha$, antileukoproteinase 1 and $\alpha$-defensins that are compounds with well-known antibacterial activity. Antileukoproteinase 1 , previously named secretory leukocyte protease inhibitor (SLPI), is an enzyme found in various mucosal secretions that protects epithelial tissues from serine proteases and has a broad-spectrum antibiotic activity [41]. Antileukoproteinase 1 is secreted during experimental mastitis in animals [42]. Given the increase of mediators in response to LPS exposure, and the changes in absolute and relative concentrations of immunological factors, breast milk immunological functions appears dramatically modified during SCM.

SCM may be viewed as an initial stage of inflammation that carries a risk of subsequent progression to clinical disease. The rarity of symptomatic mastitis as compared to the prevalence of SCM which are quite common underlines the ability of the immune response to limit local infection and preserve breastfeeding. Most of the time, SCM does not compromise breastfeeding, whereas clinical mastitis is always associated with pain, local inflammation and fever and, without appropriate support, may result in cessation of breastfeeding. The exact consequence of SCM on infant development remains to be established. A relationship between severe mammary inflammation during SCM and poor weight gain or lower breast milk intake has been reported [43] [17] [44]. SCM occurs frequently in 
one breast in human, making possible for the unaffected breast to increase the milk output to maintain milk intake. Authors have suggested that the raise of sodium and inflammation in breast milk may be associated with reluctance to accept milk from the affected breast during SCM [17]. However, these associations may also reflect inadequate milk removal rather than a consequence of SCM on infant development [15]. Troubles with suckling or painful breasts after delivery are frequent. Breastfeeding counselling [45] and antibiotic treatment [46] can be proposed as effective methods to reduce the incidence of SCM. We thought that SCM diagnosis and monitoring of biomarkers related to SCM may be important for breastfeeding support and evaluation of the impact of SCM on difficulties related to breastfeeding.

In this study breast milk environment was characterized without longitudinal analysis of breast milk composition. Sequential testing of human milk after and before SCM would help to better understand the mechanisms involved in SCM occurrence. In conclusion, our findings indicate that SCM in mature human milk is associated with dramatic changes in breast microenvironment and cytokine profiles. Th1 and pro-inflammatory-related cytokines are preferential increase. High concentrations of innate response markers suggest that SCM inflammation most likely results from bacterial exposure. We propose that SCM comprise changes in the immunological functions of the human milk aimed at limiting the risk of development of breast milk pathogen growth and clinical mastitis during breastfeeding. During SCM, cytokine imbalances in breast milk may have a notable impact on mucosal immune system and gut microbiota of the infant early in life. The consequences of this change on the immunological gut maturation and microbiota of the infants should be further explored. 


\section{MATERIAL AND METHODS}

\section{Subjects and sample collections}

Samples were collected from 44 healthy mothers included in a large infant feeding intervention cohort (Vertical Transmission Study) in South Africa [18]. The study had two enrolment sites in South Africa: one peri-urban clinic and eight seven rural clinics in Umkhanyakude district of northern KwaZulu-Natal, and one urban site on the outskirts of Durban. Enrolment, HIV testing and counseling were systematically offered to women aged of 16 years and over attending antenatal clinics. All women included in this nested study were randomly selected among HIV-uninfected women without clinical diagnosis recorded at scheduled clinic visits and none were diagnosed with symptomatic mastitis; breast health problems; fever or ill in the last seven days at the time of sample collection (see supplemental table 1 for details on patient characteristics and living conditions). Lay breastfeeding counselors provided home support for mothers during the antenatal period, around delivery, and fortnightly to six months post-delivery [47]. Mothers who chose to breastfeed were encouraged to exclusively breastfeed for the first six months. Breastfeeding counsellors were trained to diagnose and document any breast health problems at visits, including blocked ducts, nipple fissures and mastitis, but breast health problems were very few [20]. One hundred ten samples of mature breast milk (56 from left and 54 from right breast), of which 104 were paired, were collected. Thirty-four women gave one paired sample from left and right breast, four women gave two paired samples, three women gave three paired samples, and one woman gave four paired and one right sample only. For two women only a left breast milk sample was available. Milk samples were collected from 31 to 493 days post-partum (median 155 days; IQR 98-218).Milk samples were obtained by manual expression at the clinic without any relationship to feeds (i.e. a combination of fore and hind milk, and transported to the virology laboratory overnight at $4^{\circ} \mathrm{C}$ after which it was stored as whole breast milk at $-70^{\circ} \mathrm{C}$. For testing, thawed breast milk was centrifuged at $1500 \mathrm{rpm}$ for $5 \mathrm{~min}$ in sterile polypropylene tubes to separate lipids, aqueous layer and cellular components. After 
lipids were removed, an aqueous layer was collected and stored at $-70^{\circ} \mathrm{C}$ until use. The study was approved by the Biomedical Research Ethics Committee of the University of KwaZulu-Natal.

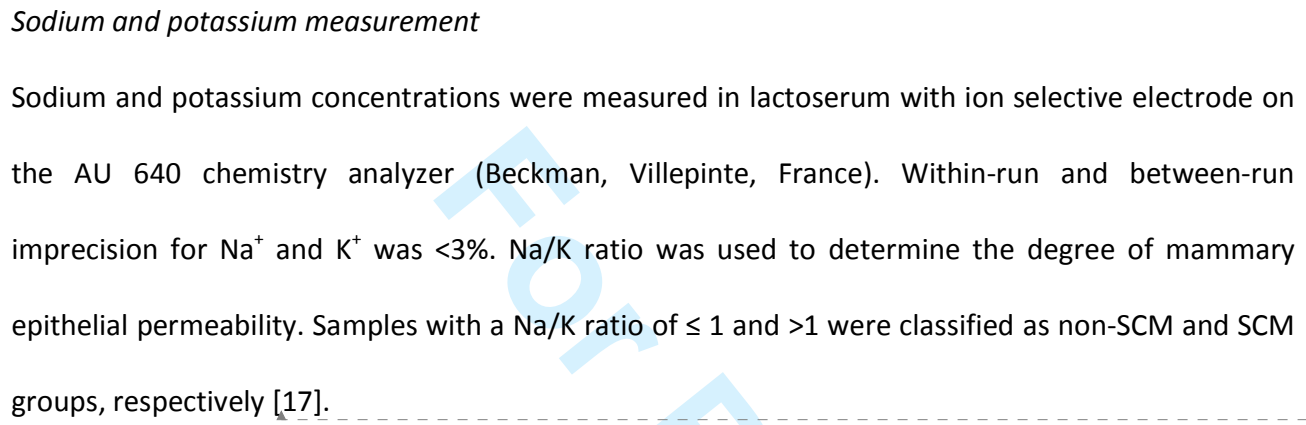


lactoferrin, IL-10, IL-1-RA) ratio was also established. $\beta 2$ microgobulin was determined by immunoturbidimetry method (Olympus apparatus, Rungis, France). Erythropoietin (EPO) levels were measured using the IMMULITE 2000 EPO assay (Diagnostic Products Corporation, Los Angeles, CA) which is an automated two-site sandwich immunoassay with chemiluminescent detection. Other immune factors and inflammatory markers were analyzed by using colorimetric sandwich enzyme linked immunosorbent assay (ELISA) as recommended by the manufacturer: lipopolysaccharide binding protein (LBP) (Hycult Biotech, Udenthe Netherlands); Alpha-defensins (Hycult Biotech); sCD14 (Hycult Biotech); S100A9 (CycLex Co., Nagano, Japan); antileukoproteinase 1 (SLPI) (R\&D Systems, Minneapolis, Minnesota); lactoferrin (Calbiochem, Dramstadt, Germany).

\section{Statistical analysis}

The values of concentrations of cytokines and other markers between SCM-positive and SCMnegative groups were compared using the nonparametric Wilcoxon-Mann-Whitney $U$ test; in order to prevent inflation of alpha-risk due to the multiplicity of tests, 0.01 was considered significant. To take into consideration data clusters defined by individual mothers, multivariate mixed models were used to evaluate relations between biomarkers concentration (dependent variable) and SCM controlled for breast milk sample side, age of child at sample collection and mother study number as random effect. ROC curves of the selected biomarkers were constructed and areas under the curve (AUC) were calculated along with their $95 \%$ confidence intervals $(95 \% \mathrm{Cl})$ using a nonparametric approach. To avoid false-positive results, a cutoff value was retained corresponding to the maximum Youden index (YI). Statistical analyses were performed using SAS statistical software (version 9, SAS Institute, Cary, NC).

Acknowledgements: We thank the participants and co-workers of the Vertical Transmission Study. 
1. Munblit D, Boyle RJ, Warner JO. Factors affecting breast milk composition and potential consequences for development of the allergic phenotype. Clin Exp Allergy 2015,45:583-601.

2. Garofalo R. Cytokines in human milk. J Pediatr 2010,156:S36-40.

3. Gasparoni A, Chirico G, De Amici M, Ravagni-Probizer M, Ciardelli L, Marchesi ME, et al. Granulocyte-marophage colony-stimulating factor in human milk. Eur J Pediatr 1996,155:69.

4. Garofalo R, Chheda S, Mei F, Palkowetz KH, Rudloff HE, Schmalstieg FC, et al. Interleukin-10 in human milk. Pediatr Res 1995,37:444-449.

5. Bosire R, Guthrie BL, Lohman-Payne B, Mabuka J, Majiwa M, Wariua G, et al. Longitudinal comparison of chemokines in breastmilk early postpartum among HIV-1-infected and uninfected Kenyan women. Breastfeed Med 2007,2:129-138.

6. Arsenault JE, Webb AL, Koulinska IN, Aboud S, Fawzi WW, Villamor E. Association between breast milk erythropoietin and reduced risk of mother-to-child transmission of HIV. J Infect Dis 2010,202:370-373.

7. Shiou SR, Yu Y, Chen S, Ciancio MJ, Petrof EO, Sun J, et al. Erythropoietin protects intestinal epithelial barrier function and lowers the incidence of experimental neonatal necrotizing enterocolitis. J Biol Chem 2011,286:12123-12132.

8. WHO. Mastitis, Causes and Management. In; 2000.

9. Riordan J, Wambach K. Breastfeeding and Human Lactation. 4th Edition ed: Jones and Bartlett Publishers; 2010.

10. Gomo E, Filteau SM, Tomkins AM, Ndhlovu P, Michaelsen KF, Friis H. Subclinical mastitis among HIV-infected and uninfected Zimbabwean women participating in a multimicronutrient supplementation trial. Trans R Soc Trop Med Hyg 2003,97:212-216.

11. Van de Perre P, Rubbo PA, Viljoen J, Nagot N, Tylleskar T, Lepage P, et al. HIV-1 Reservoirs in Breast Milk and Challenges to Elimination of Breast-Feeding Transmission of HIV-1. Sci TransI Med 2012,4:143sr143.

12. Filteau SM, Rice AL, Ball JJ, Chakraborty J, Stoltzfus R, de Francisco A, et al. Breast milk immune factors in Bangladeshi women supplemented postpartum with retinol or betacarotene. Am J Clin Nutr 1999,69:953-958.

13. Aryeetey RN, Marquis GS, Timms L, Lartey A, Brakohiapa L. Subclinical mastitis is common among Ghanaian women lactating 3 to 4 months postpartum. J Hum Lact 2008,24:263-267.

14. Jost T, Lacroix C, Braegger C, Chassard C. Impact of human milk bacteria and oligosaccharides on neonatal gut microbiota establishment and gut health. Nutr Rev 2015,73:426-437.

15. Neville MC, Allen JC, Archer PC, Casey CE, Seacat J, Keller RP, et al. Studies in human lactation: milk volume and nutrient composition during weaning and lactogenesis. Am J Clin Nutr 1991,54:81-92.

16. Morton JA. The clinical usefulness of breast milk sodium in the assessment of lactogenesis. Pediatrics 1994,93:802-806.

17. Aryeetey RN, Marquis GS, Brakohiapa L, Timms L, Lartey A. Subclinical mastitis may not reduce breastmilk intake during established lactation. Breastfeed Med 2009,4:161-166.

18. Coovadia HM, Rollins NC, Bland RM, Little K, Coutsoudis A, Bennish ML, et al. Mother-to-child transmission of HIV-1 infection during exclusive breastfeeding in the first 6 months of life: an intervention cohort study. Lancet 2007,369:1107-1116.

19. Agarwal S, Karmaus W, Davis S, Gangur V. Immune markers in breast milk and fetal and maternal body fluids: a systematic review of perinatal concentrations. I Hum Lact 2011,27:171-186. 
20. Bland RM, Becquet R, Rollins NC, Coutsoudis A, Coovadia HM, Newell ML. Breast health problems are rare in both HIV-infected and HIV-uninfected women who receive counseling and support for breast-feeding in South Africa. Clin Infect Dis 2007,45:1502-1510.

21. Chollet-Hinton LS, Stuebe AM, Casbas-Hernandez P, Chetwynd E, Troester MA. Temporal trends in the inflammatory cytokine profile of human breastmilk. Breastfeed Med 2014,9:530-537.

22. Gazzolo D, Monego G, Corvino V, Bruschettini M, Bruschettini P, Zelano G, et al. Human milk contains S100B protein. Biochim Biophys Acta 2003,1619:209-212.

23. Mange A, Tuaillon E, Viljoen J, Nagot N, Bendriss S, Bland RM, et al. Elevated concentrations of milk beta2-microglobulin are associated with increased risk of breastfeeding transmission of HIV-1 (Vertical Transmission Study). J Proteome Res 2013,12:5616-5625.

24. Regenhard P, Petzl W, Zerbe H, Sauerwein $\mathrm{H}$. The antibacterial psoriasin is induced by E. coli infection in the bovine udder. Vet Microbiol 2010,143:293-298.

25. Nussenblatt V, Lema V, Kumwenda N, Broadhead R, Neville MC, Taha TE, et al. Epidemiology and microbiology of subclinical mastitis among HIV-infected women in Malawi. Int J STD AIDS 2005,16:227-232.

26. Badiou S, Tuaillon E, Viljoen J, Escudié B, Cristol JP, Newell ML, et al. Association between breast milk fatty acids and HIV-1 transmission through breastfeeding. Prostaglandins Leukot Essent Fatty Acids 2016, in press.

27. Na YJ, Han SB, Kang JS, Yoon YD, Park SK, Kim HM, et al. Lactoferrin works as a new LPSbinding protein in inflammatory activation of macrophages. Int Immunopharmacol 2004,4:1187-1199.

28. Lucas A, Cole TJ. Breast milk and neonatal necrotising enterocolitis. Lancet 1990,336:15191523.

29. Claud EC, Lu L, Anton PM, Savidge T, Walker WA, Cherayil BJ. Developmentally regulated IkappaB expression in intestinal epithelium and susceptibility to flagellin-induced inflammation. Proc Natl Acad Sci U S A 2004,101:7404-7408.

30. Thomsen AC, Hansen KB, Moller BR. Leukocyte counts and microbiologic cultivation in the diagnosis of puerperal mastitis. Am J Obstet Gynecol 1983,146:938-941.

31. Burch J, Karmaus W, Gangur V, Soto-Ramirez N, Yousefi M, GoetzI LM. Pre- and perinatal characteristics and breast milk immune markers. Pediatr Res 2013,74:615-621.

32. Groer M, Davis $M$, Steele K. Associations between human milk SIgA and maternal immune, infectious, endocrine, and stress variables. J Hum Lact 2004,20:153-158; quiz 159-163.

33. Tomicic S, Johansson G, Voor T, Bjorksten B, Bottcher MF, Jenmalm MC. Breast milk cytokine and IgA composition differ in Estonian and Swedish mothers-relationship to microbial pressure and infant allergy. Pediatr Res 2010,68:330-334.

34. Hassiotou F, Geddes DT, Hartmann PE. Cells in human milk: state of the science. J Hum Lact 2013,29:171-182.

35. Riskin A, Almog M, Peri R, Halasz K, Srugo I, Kessel A. Changes in immunomodulatory constituents of human milk in response to active infection in the nursing infant. Pediatr Res 2012,71:220-225.

36. Cole AM, Ganz T, Liese AM, Burdick MD, Liu L, Strieter RM. Cutting edge: IFN-inducible ELRCXC chemokines display defensin-like antimicrobial activity. J Immunol 2001,167:623-627.

37. Sherry B, Espinoza M, Manogue KR, Cerami A. Induction of the chemokine beta peptides, MIP-1 alpha and MIP-1 beta, by lipopolysaccharide is differentially regulated by immunomodulatory cytokines gamma-IFN, IL-10, IL-4, and TGF-beta. Mol Med 1998,4:648657.

38. Labeta MO, Vidal $\mathrm{K}$, Nores JE, Arias M, Vita N, Morgan BP, et al. Innate recognition of bacteria in human milk is mediated by a milk-derived highly expressed pattern recognition receptor, soluble CD14. J Exp Med 2000,191:1807-1812. 
39. Buer J, Balling R. Mice, microbes and models of infection. Nat Rev Genet 2003,4:195-205.

40. Hailman E, Lichenstein HS, Wurfel MM, Miller DS, Johnson DA, Kelley M, et al. Lipopolysaccharide (LPS)-binding protein accelerates the binding of LPS to CD14. J Exp Med 1994,179:269-277.

41. Bingle CD, Vyakarnam A. Novel innate immune functions of the whey acidic protein family. Trends Immunol 2008,29:444-453.

42. Gunther J, Petzl W, Zerbe H, Schuberth HJ, Koczan D, Goetze L, et al. Lipopolysaccharide priming enhances expression of effectors of immune defence while decreasing expression of pro-inflammatory cytokines in mammary epithelia cells from cows. BMC Genomics 2012,13:17.

43. Manganaro R, Marseglia L, Mami C, Palmara A, Paolata A, Loddo S, et al. Breast milk sodium concentration, sodium intake and weight loss in breast-feeding newborn infants. Br J Nutr 2007,97:344-348.

44. Filteau SM, Lietz G, Mulokozi G, Bilotta S, Henry CJ, Tomkins AM. Milk cytokines and subclinical breast inflammation in Tanzanian women: effects of dietary red palm oil or sunflower oil supplementation. Immunology 1999,97:595-600.

45. Flores M, Filteau S. Effect of lactation counselling on subclinical mastitis among Bangladeshi women. Ann Trop Paediatr 2002,22:85-88.

46. Nussenblatt V, Kumwenda N, Lema V, Quinn T, Neville MC, Broadhead R, et al. Effect of antibiotic treatment of subclinical mastitis on human immunodeficiency virus type 1 RNA in human milk. J Trop Pediatr 2006,52:311-315.

47. Bland R, Coovadia H, Coutsoudis A, Rollins N, Newell M. Cohort profile: mamanengane or the Africa centre vertical transmission study. Int J Epidemiol 2010,39:351-360.

48. Rubbo PA, Tuaillon E, Bollore K, Foulongne V, Bourdin A, Nagot N, et al. The potential impact of CD4+ T cell activation and enhanced Th1/Th2 cytokine ratio on HIV-1 secretion in the lungs of individuals with advanced AIDS and active pulmonary infection. Clin Immunol 2011,139:142-154. 


\section{Legends}

Figure 1. Comparison of intra-individual cytokine concentration in unilateral SCM in mothers with unilateral SCM $(\mathrm{Na}+/ \mathrm{K}+\geq 1.0)$. Each subject is represented by a symbol. Each pair represents samples collected at the same time from the two mammary glands of one mother.

Figure 2. Comparison of cytokine balances between controls versus SCM milk samples. A value of 1 arbitrary unit was given to the median cytokine concentration observed in control samples ( $n=90)$, and the relative value for SCM samples are displayed proportionately $(n=18)$. (A) Pro-inflammatory versus anti-inflammatory balance in breast milk. Variation of red to orange is used for pro-inflammatory related cytokines: IL-12p40/70, IL-17, IL-6, IFN- $\gamma$ and hues of green are used for anti-inflammatory related factors: IL-1RA, erythropoietin (EPO), IL-10, lactoferrin (LACTO). (B) Th1 versus Th2 related cytokine balance in breast milk. Variation of red to orange is used for Th1 related cytokines: IFN- $y$, IFN-a, IL-15, IL-12p40/70, IL-2 and hues of blue are used for Th2 related cytokines: IL-10, IL-13, IL-5, and IL-4.

Figure 3. Determination of surrogate biomarkers to $\mathrm{Na}+\mathrm{K}+$ ratio for the diagnosis of SCM in mature breast milk. INF-y, IP-10, PS100A9 and IL-8 secretion levels were quantified in whey from samples with $\mathrm{Na}+/ \mathrm{K}+$ ratio $\leq 1$ (controls) or $\mathrm{Na} / \mathrm{K}$ ratio $>1$ (SCM). ROC curves display sensitivity versus specificity for each biomarker in identifying SCM. Green: IFN-y, AUC: 0.85; black: IP-10, AUC: 0.86, red: PS100A9, AUC: 0.77; blue: IL-8, AUC: 0.76 . 
Subclinical mastitis occurs frequently in association with dramatic changes in

\section{inflammatory/anti-inflammatory breast milk components}

Running Title: Inflammatory response during SCM

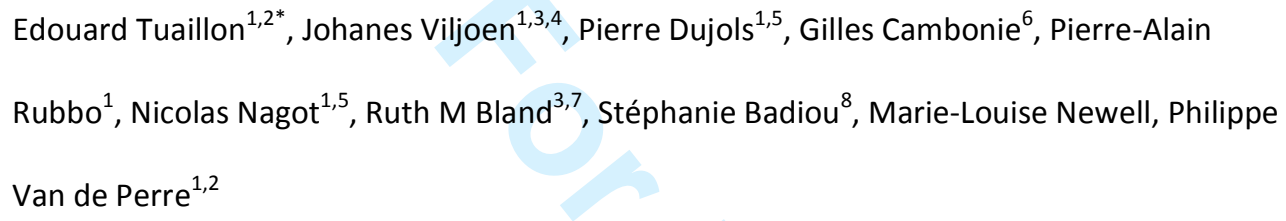




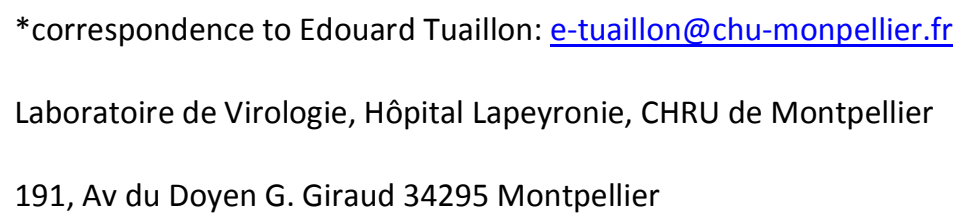




\section{Abstract}

Background: Subclinical mastitis (SCM) is a frequent, but poorly characterized entity that may influence immune development of breastfed infants. Mechanisms driving the emergence of SCM and changes in immunological content of human milk during SCM remains to be explored. In this study, the breast milk environment was to describe during SCM.

Methods: One hundred ten samples of mature breast milk were collected from 44 healthy, HIV negative mothers, included in a large infant feeding intervention cohort (ANRS 1271/Vertical Transmission Study). Immune markers related to inflammatory/anti-inflammatory balances and secreted in response to bacterial exposure were explored in SCM breast milk samples ( $\mathrm{Na} / \mathrm{K}$ ratio $>1$ ) and compared to non-SCM controls.

Results: SCM was observed in $23 \%$ of women (95\% Cl: $21-24)$ and associated with higher levels of inflammatory markers ( $\beta 2$ microgobulin, PS100A9, TNF- $\alpha$, IL-6, IL-8, IL-17 and RANTES) and Th1related cytokines (IL-2R, IL-12p40/70, IFN- $\alpha$, IFN- $\gamma$, CXCL-9, andIP-10). High levels of factors secreted in response to bacteria and lipopolysaccharide (LPS) exposure where observed in SCM breast milk samples (MIP-1 $\alpha$, MIP-1 $\beta$, LPS binding protein, $\alpha$-defensins, and antileukoproteinase 1 ).

Conclusion: SCM is associated with important changes in breast milk microenvironment, with a proinflammatory/Th1-cytokine predominant profile. During SCM, cytokine imbalances in breast milk may have a notable influence on mucosal immune system of the infant early in life. 


\section{INTRODUCTION}

Epidemiological and biological studies have proven the benefits of breastfeeding for child health. Breastfeeding have short-term and long-term health consequences for the child [1]. Breast milk down-regulates gut inflammation and promotes gut adaptation in the neonatal period when the newborn is suddenly exposed to antigens from colonizing commensal bacteria. According to clinical and experimental observations, human milk should not only be viewed as a source of nutrition and passive protection during a period of immunological immaturity, but also as a biological fluid able to modulate the immunological development of the recipient infant [2].

To date, immune factors and cytokines contained in human breast milk remain only partially characterized. High levels of interleukin-1 beta (IL-1ß), interleukin-6 (IL-6), tumor necrosis factoralpha (TNF- $\alpha$ ) and IFN- $\gamma$ were found in breast milk samples from healthy lactating mothers (3). Cytokines belonging to the CXC and CC chemokine families are also measurable in breast milk. These small chemotactic cytokines are mediators of inflammation able to attract and activate leukocytes. The presence of monocyte chemotactic protein (MCP-1), RANTES (regulated upon activation, normal T-cell expressed and secreted), and macrophage inflammatory protein 1 alpha (MIP-1 $\alpha$ ) of the CC chemokine family, as well as interleukin-8 (IL-8) of the CXC chemokine family, have all been demonstrated in breast milk [2]. These cytokines have been shown to be expressed (mRNA) and secreted by both mammary epithelial cells and breast milk leukocytes. Granulocyte-macrophage colony-stimulating factor (GM-CSF) was also identified in human breast milk [3]. In addition to these pro-inflammatory and Th1-related cytokines, interleukin-10 (IL-10), a key immunoregulatory and anti-inflammatory cytokine, has been measured in significant concentrations in lactoserum and the lipid layer of breast milk [4]. Erythropoietin (EPO) is another stimulating factor found in breast milk[5], and HIV transmission through breastfeeding is inversely related to the concentration of EPO in breast milk [6]. Alongside the well-known function of EPO to stimulate red blood cell production,
Field Code Changed

Field Code Changed

Field Code Changed 
EPO might promote the integrity of the mammary and gut epithelium through cytoprotective properties and limitation of inflammation [7].

Mastitis, a local infection associated with inflammation and increased mammary epithelial permeability, induces considerable changes in the immunological contents of milk in animals. An elevated sodium/potassium $(\mathrm{Na} / \mathrm{K})$ ratio in breast milk has been demonstrated as an indicator of mastitis. This elevated ratio, accompanied by an increased concentration of IL-8, is also frequently seen in asymptomatic lactating women, thus characterizing an episode of subclinical mastitis (SCM), which is a recently defined and poorly understood entity $[8,9]$. Studies investigating HIV transmission by breastfeeding demonstrated a high prevalence of SCM in both HIV-infected and uninfected lactating women, ranging from $10 \%$ to $45 \%$ [10]. SCM is associated with increased HIV load in breast milk of infected women and may be associated with increased risk of mother-to-child transmission of HIV [11]. Almost a quarter of breast milk samples collected during the first month of lactation, and more than $10 \%$ thereafter, present with biological features of SCM $[12,13]$. SCM may well precede symptomatic mastitis but the low frequency of clinical mastitis compared to episodes of SCM indicates that in the majority of cases the immune response is able to avoid significant breakthrough infection during lactation. The consequences of SCM on the immunological content of breast milk and the mechanisms driving the emergence of SCM need to be established. We propose that SCM induces dramatic changes in breast milk immune contents. Culture-dependent research and microbiome approaches have shown that normal human milk contains a wide range of commensal bacteria contributing to neonatal gut microbiota and potentially preventing pathogen growth [14]. Exposure to pathogen microorganisms may trigger the immunological changes seen during SCM. However, this assumption is challenged by the fact that conditions such as cessation of breastfeeding, micronutrient deficiencies, milk stasis (engorgement) or systemic infections may also be responsible for a raised $\mathrm{Na} / \mathrm{K}$ ratio [15-17].
Field Code Changed

Field Code Changed

Field Code Changed

Field Code Changed

Field Code Changed

Field Code Changed

Field Code Changed 
The aim of our study was to describe the breast milk environment during SCM in healthy mothers: the frequency of the phenomenon and changes in the Th1 versus Th2 related factors and inflammatory versus anti-inflammatory equilibriums that accompany it. This study was nested within a large mother-to-child HIV transmission study, but was focused on HIV-uninfected women and their infants only [18]. We observed that some immunological parameters contained in breast milk are robust markers of SCM. Changes in Th1/Th2 and inflammatory/anti-inflammatory balance during SCM may influence gut homeostasis in newborns. In view of the potential association between bacterial exposure and the onset of SCM, we tested immunological parameters associated with innate responses to LPS exposure.

\section{RESULTS}

Frequency of unilateral and bilateral SCM during lactation

The median $\mathrm{Na}+$ and $\mathrm{K}+$ concentrations were 10 (IQR 9-11.8) and 12.8 (IQR 11.5-14.3) mmol/L respectively $(\mathrm{n}=110)$. The median $\mathrm{Na} / \mathrm{K}$ ratio was 0.77 (IQR 0.69-0.92). An episode of SCM as defined by a $\mathrm{Na} / \mathrm{K}$ ratio of $>1.0$ was observed in 10 of the 44 women ( $23 \% ; 95 \% \mathrm{Cl}: 21-24 \%)$, and 18 of 110 samples (16\%; 95\% Cl: 16\%-17\%). This abnormality in mammary epithelial permeability was bilateral in 5 cases, and unilateral in 8 cases, with one woman having one episode of bilateral and one episode of unilateral SCM, and another woman having three episodes of unilateral SCM.

\section{Assessment of bioactive components in human milk.}

Of the 25 cytokines analyzed by multiplex microbeads assay, most were measurable in breast milk with concentrations within the range of quantification of the assay. However, TNF- $\alpha$ was quantifiable only in a minor proportion of samples $(20 / 113 ; 18 \%)$, and IFN- $\alpha$ in $32 / 113$ samples (28\%). IL-1 $\beta$ were below the lower limit of detection in 16/113 (14\%) samples, and Eotaxin in 19/113 (17\%) of samples tested. By comparison with references values observed in blood, breast milk samples from the 


\section{Immunological components increased during SCM}

SCM induced numerous changes in immunological content of breast milk (Table 1). Most factors associated with inflammation ( $\beta 2$ microgobulin, PS100A9, TNF- $\alpha$, IL-6, IL-8, IL-17 and RANTES) were significantly increased in SCM samples as compared to control samples after adjusting for multiple comparisons. Of the cytokines involved in the Th1 response, 6 out of 8 were also significantly increased in the SCM group (IL-2R, IL-12p40/70, IFN- $\gamma$, IFN- $\alpha$, monokine induced by gamma interferon (MIG or CXCL-9), and IP-10 ( $\mathrm{p}<0.001)$. Regarding Th2-related cytokines, only IL-4 was found in significantly higher concentrations in samples from the SCM group than in controls ( $p<0.001)$. Lactoferrin, IL-10 and EPO, three factors associated with anti-inflammatory properties of breast milk, were not significantly increased during SCM. The median level of IL-1RA was 3-fold higher in the SCM group than in controls $(p<0.001)$.

In 7 women with unilateral SCM, within-woman comparison of breast milk showed that markers of inflammation IL-8, IP-10, IFN- $\gamma$ and IL-12p40/70 were generally more elevated in the side affected by SCM (Figure 1). The differences were significant for IL-12p40/70 (median 58.1 pg/mL, IQR 41.7-87.6, $\mathrm{p}=0.046)$ and IL-8 (median $488.6 \mathrm{pg} / \mathrm{mL}, \mathrm{IQR} 225.7-1324.1, \mathrm{p}=0.031)$.

\section{Alterations in the Th1/Th2 and pro-/anti-inflammatory balances during SCM}

The relative concentrations of Th1/Th2 and pro-/anti-inflammatory related markers were analyzed to describe changes of breast milk environment during SCM. The ratio of pro- versus anti-inflammatory related factors was increased during SCM although the increase seen in IL-1RA and lactoferrin 
partially compensated for the high concentration of pro-inflammatory related cytokines (Figure 2, panel A).

Changes in the ratio of Th1/Th2-related cytokines were also observed in the SCM group as compared to controls with a predominant elevation of cytokines that belong to the Th1-type immune response (Figure 2, panel B).

\begin{abstract}
A Th1 and pro-inflammatory signature can be used to identify SCM
Additionally, we explored the possibility to appropriately identify SCM with factors related to proinflammatory (IL-8 and PS100A9) and Th1 (IFN- $\nu$ and IP-10) responses in breast milk using receiver operating characteristic (ROC curves). The greatest area under curve was obtained with IP-10 (AUC 0.86) and IFN- $\gamma$ (AUC 0.85). IL-8 and PS100A9 offered also good discriminatory capacity between SCM and control samples (AUC 0.78 and 0.77 , respectively) (Figure 3 ). For example, the sensitivity and specificity were $70 \%$ and $94 \%$ respectively with a cut off value of $2551 \mathrm{pg} / \mathrm{mL}$ for IP-10. Using a cut off value of $1092 \mathrm{pg} / \mathrm{mL}$ for IP-10, the sensitivity and specificity were 94\% and 64\% respectively. Lower performances were obtained with the other factors found in significantly higher concentrations during SCM by comparison with controls such as IL-12p40/70, IFN- $\alpha$ and IL-17 (data not shown).
\end{abstract}

\title{
Relationship between SCM and immunological factors secreted in response to bacterial exposure
}

A combination of markers secreted in response to LPS and bacterial antigens were tested to demonstrate the association between bacterial exposure and SCM, namely: MIP-1 $\alpha$ and MIP-1 $\beta$, MCP-1, sCD14, LPS binding protein, antileukoproteinase 1 and $\alpha$-defensins.

SCM samples were associated with high concentrations of factors associated with bacterial exposure (Table 2). Levels of factors secreted in response to bacteria and LPS exposure where significantly higher in SCM samples by comparison to normal breast milk, for: MIP-1 $\alpha$, MIP-1 $\beta$, LPS binding 


\section{DISCUSSION}

Breast milk contains numerous immunological factors that play a pivotal role in modulating infant's mucosal immune system as well as susceptibility to pathogens [11]. Some of these highly active factors are found at higher concentrations than in blood $[2,19]$, highlighting the importance of the immunomodulatory functions of breast milk. Consequently, changes in immune responses during SCM may impact on breast milk immunomodulatory functions. In this study we observed that a predominant Th1 and pro-inflammatory signature characterized SCM. Furthermore, some of the human milk immune components had good performance to identify SCM when used as surrogate makers of $\mathrm{Na}+\mathrm{K}+$ ratio. Finally, markers of the immune response against LPS were associated with SCM suggesting that bacteria exposure was involved.

A raised $\mathrm{Na}+/ \mathrm{K}+$ ratio that characterizes $\mathrm{SCM}$ was found in almost a quarter of mothers, a frequency comparable with observations made in other settings $[12,13]$ despite the intensive efforts made to promote good breastfeeding practices in this clinical study [20].

Although some levels of inflammation had already been suggested in association with SCM, our study demonstrates that a raised $\mathrm{Na}+/ \mathrm{K}+$ ratio is associated with a full spectrum inflammatory process in 
the mammary gland consisting of higher levels of most of the inflammatory markers (e.g. $\beta 2$ microglobulin, protein S100A9, IL-6, IL-8 and TNF- $\alpha$ ), when compared to normal breast milk samples. A clear inflammatory process was also observed in at least two samples with a $\mathrm{Na}+\mathrm{K}+$ ratio below 1 . Thus, additional parameters such as IP-10, IL-8, or protein S100A9 may be used in combination with the $\mathrm{Na}+\mathrm{K}+$ ratio to better define SCM. Samples were collected from 1 to 16 months after delivery. Whereas cytokine expression decreases during the first month of lactation in transitional breast milk, immune components appear relatively stable in mature breast milk [21].

To our knowledge, this is the first study to show the clear association of protein S100A9 with the immune responses found in human SCM. Protein S100, secreted by mammary epithelial cells and lymphocytes, are found at high concentrations in mature breast milk [22]. In a previous study based on a quantitative proteomic approach we observed an association between protein S100A9 in breast milk and HIV mother to child transmission before 4 month of age [23]. These acidic calcium-binding proteins are involved in brain development of the infant and inflammation. Studies in animal models of mastitis suggest that proteins of the $\mathrm{S} 100$ family may also have anti-bacterial activity [24]. High levels of IL-8 in breast milk have been previously described in SCM $[9,12,25]$. IL-8 is a chemokine produced by macrophages and epithelial cells, both of which are an important fraction of the breast milk cellular composition [11]. IL-8 is a major mediator of the inflammatory response playing a key role in the innate response. Side by side comparison of cytokines levels indicated that SCM is a local event. Besides pro-inflammatory-related factors, we observed higher levels of most of the Th1 cytokines including a dramatic increase of $\mid L-12 p 40 / 70, I F N-\alpha, I F N-\gamma$, IP -10 and $M \mid G$ in the SCM group. Breast milk IP-10 and MIG are secreted in response to IFN- $\gamma$. IP-10 is produced by a variety of cells, including monocytes, fibroblasts and endothelial cells, and MIG mainly by lymphocytes. Both chemokines target the CXCR-3 receptor and contribute to the recruitment and activation of T lymphocytes, natural killer cells, and monocytes. As illustrated by the increased levels of Th1 cytokines, a cytotoxic T lymphocyte response is promoted during the course of SCM. 


\begin{abstract}
In contrast to high levels of Th1-related cytokines, and except for IL-4, SCM was not associated with
\end{abstract} significantly higher concentrations of Th2 cytokines (IL-5, IL-10, IL-13) as compared to controls. Hence, the cytokine profile in breast milk appeared to be dominated by the Th1 response during SCM. Of breast milk anti-inflammatory mediators, SCM was associated with a higher level of IL1-RA but with no significant rise of IL-10, EPO or lactoferrin. The high concentrations of Th1 and proinflammatory-related cytokines may be only partially compensated for by changes in Th2 and antiinflammatory cytokine levels. Relative changes in concentrations of Th1- vs Th2-related cytokines and pro- vs anti-inflammatory factors in breast milk can be viewed as disequilibrium in breast milk immunological components during SCM. In addition, inflammation in breast milk interplays with breast milk fatty acid profile. Hence, we recently observed that IL15, IP10, and $\beta 2$ microglobulin, correlate positively for cis-vaccenic acid, and negatively for eicosatrienoic acid in breast milk collected from HIV infected mothers [26].

Field Code Changed Regarding the pivotal role of breast milk in the maturation of gut and mucosal-associated lymphoid tissue in the newborn, these findings raise the question of the impact of SCM on the infant. Physiologically, it is thought that breast milk provides protective anti-inflammatory factors containing the propensity of the immature human small intestine to respond to commensal colonizing bacteria by an excessive inflammatory response [27]. In preterm infants breast milk limits the incidence of necrotizing enterocolitis [28]. This disease of the immature bowel is probably induced by an inflammatory response. A critical balance between nuclear factor kappa B (NF-KB) activation and inhibition is important to allow appropriate defense against pathogens, yet avoid host damaging inflammatory responses to the commensal flora. During necrotizing enterocolitisa defect in NF-KB regulation with an excessive production of inflammatory cytokines in responses to the commensal flora is observed [7]. Foll-like receptor (TLR) activation, as well as TNF- $\alpha$ - and IL-1ß activate NF-kB. In an animal model colostral whey reduced the IL- 8 inflammatory response of fetal human xenografts after an inflammatory stimulus with IL-1 $\beta$ and the luminal expression of TLR-4, which is an important 
cell receptor of the innate inflammatory response [29]. In vitro EPO and IL-10 used at concentrations found in breast milk are able to negatively control the IL- 8 secretion by a fetal human enterocyte cell line. EPO also reduces the susceptibility to IFN- $\gamma$-induced experimental neonatal necrotizing lesions [7]. Lactoferrin reduces the production of inflammatory cytokines by monocytes by inhibiting activation through NF-KB [27].

Milk stasis is classically considered as the primary cause of mastitis and may progress to infection [8, 9]. It has been proposed to classify mastitis as mastitis-milk stasis, -infectious, and -noninfectious. This classification is originally based on work performed by Thomsen and colleagues that analyzed leukocyte count and bacteria in milk from breasts with clinical signs of mastitis in the 1980's [30]. Recent studies have shown that subclinical mastitis is much more frequent than clinical mastitis. Inflammation in human milk may be influenced by a large number of causes. Allergy [31] and infection [32] of the mother impact on breast milk inflammation markers. Maternal country of origin [33] and stress may also influence breast milk contents. Studies of Hassiotou F et al. [34], and Riskin A et al. [35], have reported a raise in leukocyte count, antibodies and inflammation markers in mothers' breast milk during active infection in nursing infants, supporting a very dynamic nature of the immune defense provided by breastfeeding in mother-infant dyads.

To investigate bacterial exposure as the main cause of $\mathrm{SCM}$, we explored the relationship between the $\mathrm{Na} / \mathrm{K}$ ratio and anti-microbial factors secreted in response to bacterial antigen exposure. During SCM we observed high levels of mediators related to the innate response to bacteria and LPS including MIP-1 $\alpha$, MIP-1 $\beta$, MCP-1, LBP, sCD14, antileukoproteinase 1 and $\alpha$-defensins. The rise of MIG and IP-10 that have defensin-like functions against bacteria [36] suggest that bacterial exposure is involved in SCM. MIP-1 $\alpha$ and MIP-1 $\beta$ are also secreted by macrophages after stimulation by bacterial toxins [37].

SCD14 is a pattern recognition receptor playing a pivotal role in the recognition of cell activation induced by microbial cell wall components of bacteria. SCD14 is present in high concentrations in
Field Code Changed

Field Code Changed

Field Code Changed

Field Code Changed

Field Code Changed
Field Code Changed

Field Code Changed

Field Code Changed

Field Code Changed

Field Code Changed

Field Code Changed 
human milk where it is a key mediator of innate responses [38]. SCD14 is believed to regulate microbial growth in the neonatal gut and is expressed mainly by macrophages and to a lesser extent by neutrophil granulocytes. sCD14 in human milk is a co-receptor for TLR 4 which detects gramnegative bacteria through LPS fixation and confers LPS-responsiveness to cells that do not express CD14 [39].

To our knowledge this is the first report measuring LBP during human SCM. Our findings suggest that LBP is dramatically increased during SCM, and is therefore associated with the innate response mediated by SCD14 in breast milk during SCM. LBP facilitates delivery of endotoxin aggregates to sCD14 to form monomeric endotoxin-sCD14 complexes and subsequent interactions of endotoxinSCD14 with TLR4. However, LBP is present at low concentrations in normal human breast milk [38], leading to a more controlled immune response against bacteria. Indeed, SCD14 can mediate CD14negative cell activation by LPS in the absence of LBP, albeit with slower kinetics [40]. However, we observed a median level of LBP that was 5-fold higher during SCM by comparison with normal milk, whereas SCD14 was 2 fold higher in the SCM group.

Besides LBP, and by comparison with normal breast milk, SCM is also associated with higher levels of MIP-1 $\alpha$, antileukoproteinase 1 and $\alpha$-defensins that are compounds with well-known antibacterial activity. Antileukoproteinase 1, previously named secretory leukocyte protease inhibitor (SLPI), is an enzyme found in various mucosal secretions that protects epithelial tissues from serine proteases and has a broad-spectrum antibiotic activity [41]. Antileukoproteinase 1 is secreted during experimental mastitis in animals [42]. $\alpha$-defensins are microbicidal peptides produced notably by neutrophil granulocytes in response to microbial exposure. Given the increase of mediators in response to LPS exposure, and the changes in absolute and relative concentrations of immunological factors, breast milk immunological functions appears dramatically modified during SCM.

SCM may be viewed as an initial stage of inflammation that carries a risk of subsequent progression to clinical disease. The rarity of symptomatic mastitis as compared to the prevalence of SCM which
Field Code Changed

Field Code Changed

Field Code Changed

Field Code Changed 
are quite common underlines the ability of the immune response to limit local infection and preserve breastfeeding. Most of the time, SCM does not compromise breastfeeding, whereas clinical mastitis is always associated with pain, local inflammation and fever and, without appropriate support, may result in cessation of breastfeeding. The exact consequence of SCM on infant development remains to be established. A relationship between severe mammary inflammation during SCM and poor weight gain or lower breast milk intake has been reported [43] [17] [44]. SCM occurs frequently in one breast in human, making possible for the unaffected breast to increase the milk output to maintain milk intake. Authors have suggested that the raise of sodium and inflammation in breast milk may be associated with reluctance to accept milk from the affected breast during SCM [17].

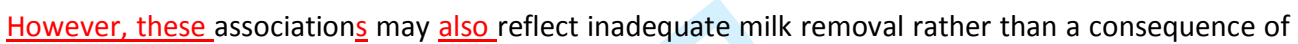
SCM on infant development [15]. Troubles with suckling or painful breasts after delivery are frequent. Breastfeeding counselling [45] and antibiotic treatment [46] can be proposed as effective methods to reduce the incidence of SCM. We thought that SCM diagnosis and monitoring of biomarkers related to SCM may be important for breastfeeding support and evaluation of the impact of SCM on difficulties related to breastfeeding.

In this study breast milk environment was characterized without longitudinal analysis of breast milk composition. Sequential testing of human milk after and before SCM would help to better understand the mechanisms involved in SCM occurrence._In conclusion, our findings indicate that SCM in mature human milk is associated with dramatic changes in breast microenvironment and cytokine profiles. Th1 and pro-inflammatory-related cytokines are preferential increase. High concentrations of innate response markers suggest that SCM inflammation most likely results from bacterial exposure. We propose that SCM comprise changes in the immunological functions of the human milk aimed at limiting the risk of development of breast milk pathogen growth and clinical mastitis during breastfeeding. During SCM, cytokine imbalances in breast milk may have a notable impact on mucosal immune system and gut microbiota of the infant early in life. The consequences 

explored. 


\section{MATERIAL AND METHODS}

Subjects and sample collections

Samples were collected from 44 healthy mothers included in a large infant feeding intervention cohort (Vertical Transmission Study) in South Africa [18]. The study had two enrolment sites in South Africa: one peri-urban clinic and eight seven rural clinics in Umkhanyakude district of northern KwaZulu-Natal, and one urban site on the outskirts of Durban. Enrolment, HIV testing and counseling were systematically offered to women aged of 16 years and over attending antenatal clinics. All women included in this nested study were randomly selected among HIV-uninfected women without clinical diagnosis recorded at scheduled clinic visits and none were diagnosed with symptomatic mastitis; breast health problems; fever or ill in the last seven days -at the time of sample collection (see supplemental table 1 for details on patient characteristics and living conditions). Lay breastfeeding counselors provided home support for mothers during the antenatal period, around delivery, and fortnightly to six months post-delivery [47]. Mothers who chose to breastfeed were encouraged to exclusively breastfeed for the first six months. Breastfeeding counsellors were trained to diagnose and document any breast health problems at visits, including blocked ducts, nipple fissures and mastitis, but breast health problems were very few [20]. One hundred ten samples of mature breast milk (56 from left and 54 from right breast), of which 104 were paired, were collected. Thirty-four women gave one paired sample from left and right breast, four women gave two paired samples, three women gave three paired samples, and one woman gave four paired and one right sample only. For two women only a left breast milk sample was available. Milk samples were collected from 31 to 493 days post-partum (median 155 days; IQR 98-218).Milk samples were obtained by manual expression at the clinic without any relationship to feeds (i.e. a combination of fore and hind milk, and transported to the virology laboratory overnight at $4^{\circ} \mathrm{C}$ after which it was stored as whole breast milk at $-70^{\circ} \mathrm{C}$. For testing, thawed breast milk was centrifuged at $1500 \mathrm{rpm}$ for $5 \mathrm{~min}$ in sterile polypropylene tubes to separate lipids, aqueous layer and cellular components. After 
lipids were removed, an aqueous layer was collected and stored at $-70^{\circ} \mathrm{C}$ until use. The study was approved by the Biomedical Research Ethics Committee of the University of KwaZulu-Natal.

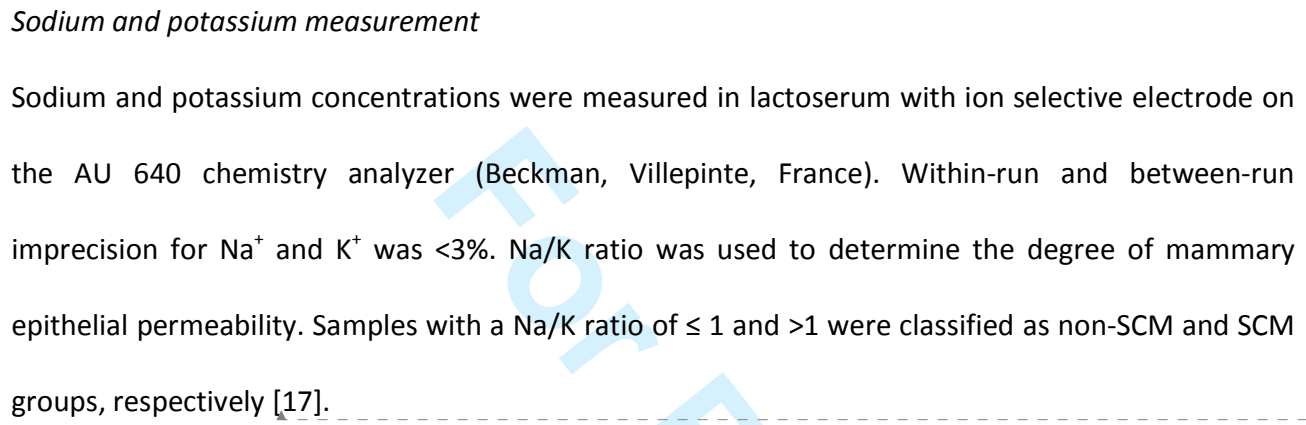


lactoferrin, IL-10, IL-1-RA) ratio was also established. $\beta 2$ microgobulin was determined by immunoturbidimetry method (Olympus apparatus, Rungis, France). Erythropoietin (EPO) levels were measured using the IMMULITE 2000 EPO assay (Diagnostic Products Corporation, Los Angeles, CA) which is an automated two-site sandwich immunoassay with chemiluminescent detection. Other immune factors and inflammatory markers were analyzed by using colorimetric sandwich enzyme linked immunosorbent assay (ELISA) as recommended by the manufacturer: lipopolysaccharide binding protein (LBP) (Hycult Biotech, Udenthe Netherlands); Alpha-defensins (Hycult Biotech); sCD14 (Hycult Biotech); S100A9 (CycLex Co., Nagano, Japan); antileukoproteinase 1 (SLPI) (R\&D Systems, Minneapolis, Minnesota); lactoferrin (Calbiochem, Dramstadt, Germany).

\section{Statistical analysis}

The values of concentrations of cytokines and other markers between SCM-positive and SCMnegative groups were compared using the nonparametric Wilcoxon-Mann-Whitney $U$ test; in order to prevent inflation of alpha-risk due to the multiplicity of tests, 0.01 was considered significant. To take into consideration data clusters defined by individual mothers, multivariate mixed models were used to evaluate relations between biomarkers concentration (dependent variable) and SCM controlled for breast milk sample side, age of child at sample collection and mother study number as random effect. ROC curves of the selected biomarkers were constructed and areas under the curve (AUC) were calculated along with their $95 \%$ confidence intervals $(95 \% \mathrm{Cl})$ using a nonparametric approach. To avoid false-positive results, a cutoff value was retained corresponding to the maximum Youden index (YI). Statistical analyses were performed using SAS statistical software (version 9, SAS Institute, Cary, NC).

Acknowledgements: We thank the participants and co-workers of the Vertical Transmission Study. 
1. Munblit D, Boyle RJ, Warner JO. Factors affecting breast milk composition and potential consequences for development of the allergic phenotype. Clin Exp Allergy 2015,45:583-601.

2. Garofalo R. Cytokines in human milk. J Pediatr 2010,156:S36-40.

3. Gasparoni A, Chirico G, De Amici M, Ravagni-Probizer M, Ciardelli L, Marchesi ME, et al. Granulocyte-marophage colony-stimulating factor in human milk. Eur J Pediatr 1996,155:69.

4. Garofalo R, Chheda S, Mei F, Palkowetz KH, Rudloff HE, Schmalstieg FC, et al. Interleukin-10 in human milk. Pediatr Res 1995,37:444-449.

5. Bosire R, Guthrie BL, Lohman-Payne B, Mabuka J, Majiwa M, Wariua G, et al. Longitudinal comparison of chemokines in breastmilk early postpartum among HIV-1-infected and uninfected Kenyan women. Breastfeed Med 2007,2:129-138.

6. Arsenault JE, Webb AL, Koulinska IN, Aboud S, Fawzi WW, Villamor E. Association between breast milk erythropoietin and reduced risk of mother-to-child transmission of HIV. J Infect Dis 2010,202:370-373.

7. Shiou SR, Yu Y, Chen S, Ciancio MJ, Petrof EO, Sun J, et al. Erythropoietin protects intestinal epithelial barrier function and lowers the incidence of experimental neonatal necrotizing enterocolitis. J Biol Chem 2011,286:12123-12132.

8. WHO. Mastitis, Causes and Management. In; 2000.

9. Riordan J, Wambach K. Breastfeeding and Human Lactation. 4th Edition ed: Jones and Bartlett Publishers; 2010.

10. Gomo E, Filteau SM, Tomkins AM, Ndhlovu P, Michaelsen KF, Friis H. Subclinical mastitis among HIV-infected and uninfected Zimbabwean women participating in a multimicronutrient supplementation trial. Trans R Soc Trop Med Hyg 2003,97:212-216.

11. Van de Perre P, Rubbo PA, Viljoen J, Nagot N, Tylleskar T, Lepage P, et al. HIV-1 Reservoirs in Breast Milk and Challenges to Elimination of Breast-Feeding Transmission of HIV-1. Sci TransI Med 2012,4:143sr143.

12. Filteau SM, Rice AL, Ball JJ, Chakraborty J, Stoltzfus R, de Francisco A, et al. Breast milk immune factors in Bangladeshi women supplemented postpartum with retinol or betacarotene. Am J Clin Nutr 1999,69:953-958.

13. Aryeetey RN, Marquis GS, Timms L, Lartey A, Brakohiapa L. Subclinical mastitis is common among Ghanaian women lactating 3 to 4 months postpartum. J Hum Lact 2008,24:263-267.

14. Jost T, Lacroix C, Braegger C, Chassard C. Impact of human milk bacteria and oligosaccharides on neonatal gut microbiota establishment and gut health. Nutr Rev 2015,73:426-437.

15. Neville MC, Allen JC, Archer PC, Casey CE, Seacat J, Keller RP, et al. Studies in human lactation: milk volume and nutrient composition during weaning and lactogenesis. Am J Clin Nutr 1991,54:81-92.

16. Morton JA. The clinical usefulness of breast milk sodium in the assessment of lactogenesis. Pediatrics 1994,93:802-806.

17. Aryeetey RN, Marquis GS, Brakohiapa L, Timms L, Lartey A. Subclinical mastitis may not reduce breastmilk intake during established lactation. Breastfeed Med 2009,4:161-166.

18. Coovadia HM, Rollins NC, Bland RM, Little K, Coutsoudis A, Bennish ML, et al. Mother-to-child transmission of HIV-1 infection during exclusive breastfeeding in the first 6 months of life: an intervention cohort study. Lancet 2007,369:1107-1116.

19. Agarwal S, Karmaus W, Davis S, Gangur V. Immune markers in breast milk and fetal and maternal body fluids: a systematic review of perinatal concentrations. I Hum Lact 2011,27:171-186. 
20. Bland RM, Becquet R, Rollins NC, Coutsoudis A, Coovadia HM, Newell ML. Breast health problems are rare in both HIV-infected and HIV-uninfected women who receive counseling and support for breast-feeding in South Africa. Clin Infect Dis 2007,45:1502-1510.

21. Chollet-Hinton LS, Stuebe AM, Casbas-Hernandez P, Chetwynd E, Troester MA. Temporal trends in the inflammatory cytokine profile of human breastmilk. Breastfeed Med 2014,9:530-537.

22. Gazzolo D, Monego G, Corvino V, Bruschettini M, Bruschettini P, Zelano G, et al. Human milk contains S100B protein. Biochim Biophys Acta 2003,1619:209-212.

23. Mange A, Tuaillon E, Viljoen J, Nagot N, Bendriss S, Bland RM, et al. Elevated concentrations of milk beta2-microglobulin are associated with increased risk of breastfeeding transmission of HIV-1 (Vertical Transmission Study). J Proteome Res 2013,12:5616-5625.

24. Regenhard P, Petzl W, Zerbe H, Sauerwein $\mathrm{H}$. The antibacterial psoriasin is induced by E. coli infection in the bovine udder. Vet Microbiol 2010,143:293-298.

25. Nussenblatt V, Lema V, Kumwenda N, Broadhead R, Neville MC, Taha TE, et al. Epidemiology and microbiology of subclinical mastitis among HIV-infected women in Malawi. Int J STD AIDS 2005,16:227-232.

26. Badiou S, Tuaillon E, Viljoen J, Escudié B, Cristol JP, Newell ML, et al. Association between breast milk fatty acids and HIV-1 transmission through breastfeeding. Prostaglandins Leukot Essent Fatty Acids 2016, in press.

27. Na YJ, Han SB, Kang JS, Yoon YD, Park SK, Kim HM, et al. Lactoferrin works as a new LPSbinding protein in inflammatory activation of macrophages. Int Immunopharmacol 2004,4:1187-1199.

28. Lucas A, Cole TJ. Breast milk and neonatal necrotising enterocolitis. Lancet 1990,336:15191523.

29. Claud EC, Lu L, Anton PM, Savidge T, Walker WA, Cherayil BJ. Developmentally regulated IkappaB expression in intestinal epithelium and susceptibility to flagellin-induced inflammation. Proc Natl Acad Sci U S A 2004,101:7404-7408.

30. Thomsen AC, Hansen KB, Moller BR. Leukocyte counts and microbiologic cultivation in the diagnosis of puerperal mastitis. Am J Obstet Gynecol 1983,146:938-941.

31. Burch J, Karmaus W, Gangur V, Soto-Ramirez N, Yousefi M, GoetzI LM. Pre- and perinatal characteristics and breast milk immune markers. Pediatr Res 2013,74:615-621.

32. Groer M, Davis M, Steele K. Associations between human milk SlgA and maternal immune, infectious, endocrine, and stress variables. J Hum Lact 2004,20:153-158; quiz 159-163.

33. Tomicic S, Johansson G, Voor T, Bjorksten B, Bottcher MF, Jenmalm MC. Breast milk cytokine and IgA composition differ in Estonian and Swedish mothers-relationship to microbial pressure and infant allergy. Pediatr Res 2010,68:330-334.

34. Hassiotou F, Geddes DT, Hartmann PE. Cells in human milk: state of the science. J Hum Lact 2013,29:171-182.

35. Riskin A, Almog M, Peri R, Halasz K, Srugo I, Kessel A. Changes in immunomodulatory constituents of human milk in response to active infection in the nursing infant. Pediatr Res 2012,71:220-225.

36. Cole AM, Ganz T, Liese AM, Burdick MD, Liu L, Strieter RM. Cutting edge: IFN-inducible ELRCXC chemokines display defensin-like antimicrobial activity. J Immunol 2001,167:623-627.

37. Sherry B, Espinoza M, Manogue KR, Cerami A. Induction of the chemokine beta peptides, MIP-1 alpha and MIP-1 beta, by lipopolysaccharide is differentially regulated by immunomodulatory cytokines gamma-IFN, IL-10, IL-4, and TGF-beta. Mol Med 1998,4:648657.

38. Labeta MO, Vidal $\mathrm{K}$, Nores JE, Arias M, Vita N, Morgan BP, et al. Innate recognition of bacteria in human milk is mediated by a milk-derived highly expressed pattern recognition receptor, soluble CD14. J Exp Med 2000,191:1807-1812. 
39. Buer J, Balling R. Mice, microbes and models of infection. Nat Rev Genet 2003,4:195-205.

40. Hailman E, Lichenstein HS, Wurfel MM, Miller DS, Johnson DA, Kelley M, et al. Lipopolysaccharide (LPS)-binding protein accelerates the binding of LPS to CD14. J Exp Med 1994,179:269-277.

41. Bingle CD, Vyakarnam A. Novel innate immune functions of the whey acidic protein family. Trends Immunol 2008,29:444-453.

42. Gunther J, Petzl W, Zerbe H, Schuberth HJ, Koczan D, Goetze L, et al. Lipopolysaccharide priming enhances expression of effectors of immune defence while decreasing expression of pro-inflammatory cytokines in mammary epithelia cells from cows. BMC Genomics 2012,13:17.

43. Manganaro R, Marseglia L, Mami C, Palmara A, Paolata A, Loddo S, et al. Breast milk sodium concentration, sodium intake and weight loss in breast-feeding newborn infants. Br J Nutr 2007,97:344-348.

44. Filteau SM, Lietz G, Mulokozi G, Bilotta S, Henry CJ, Tomkins AM. Milk cytokines and subclinical breast inflammation in Tanzanian women: effects of dietary red palm oil or sunflower oil supplementation. Immunology 1999,97:595-600.

45. Flores M, Filteau S. Effect of lactation counselling on subclinical mastitis among Bangladeshi women. Ann Trop Paediatr 2002,22:85-88.

46. Nussenblatt V, Kumwenda N, Lema V, Quinn T, Neville MC, Broadhead R, et al. Effect of antibiotic treatment of subclinical mastitis on human immunodeficiency virus type 1 RNA in human milk. J Trop Pediatr 2006,52:311-315.

47. Bland R, Coovadia H, Coutsoudis A, Rollins N, Newell M. Cohort profile: mamanengane or the Africa centre vertical transmission study. Int J Epidemiol 2010,39:351-360.

48. Rubbo PA, Tuaillon E, Bollore K, Foulongne V, Bourdin A, Nagot N, et al. The potential impact of CD4+ T cell activation and enhanced Th1/Th2 cytokine ratio on HIV-1 secretion in the lungs of individuals with advanced AIDS and active pulmonary infection. Clin Immunol 2011,139:142-154. 


\section{Legends}

Figure 1. Comparison of intra-individual cytokine concentration in unilateral SCM in mothers with unilateral SCM $(\mathrm{Na}+/ \mathrm{K}+\geq 1.0)$. Each subject is represented by a symbol. Each pair represents samples collected at the same time from the two mammary glands of one mother.

Figure 2. Comparison of cytokine balances between controls versus SCM milk samples. A value of 1 arbitrary unit was given to the median cytokine concentration observed in control samples $(n=90)$, and the relative value for SCM samples are displayed proportionately $(n=18)$. (A) Pro-inflammatory versus anti-inflammatory balance in breast milk. Variation of red to orange is used for pro-inflammatory related cytokines: IL-12p40/70, IL-17, IL-6, IFN- $\gamma$ and hues of green are used for anti-inflammatory related factors: IL-1RA, erythropoietin (EPO), IL-10, lactoferrin (LACTO). (B) Th1 versus Th2 related cytokine balance in breast milk. Variation of red to orange is used for Th1 related cytokines: IFN- $y$, IFN- $\alpha$, IL-15, IL-12p40/70, IL-2 and hues of blue are used for Th2 related cytokines: IL-10, IL-13, IL-5, and IL-4.

Figure 3. Determination of surrogate biomarkers to $\mathrm{Na}+\mathrm{K}+$ ratio for the diagnosis of $\mathrm{SCM}$ in mature breast milk. INF-y, IP-10, PS100A9 and IL-8 secretion levels were quantified in whey from samples with $\mathrm{Na}+/ \mathrm{K}+$ ratio $\leq 1$ (controls) or $\mathrm{Na} / \mathrm{K}$ ratio $>1$ (SCM). ROC curves display sensitivity versus specificity for each biomarker in identifying SCM. Green: IFN-y, AUC: 0.85; black: IP-10, AUC: 0.86, red: PS100A9, AUC: 0.77; blue: IL-8, AUC: 0.76 . 
Supplemental table 1. Characteristics of women, according to subclinical mastitis.

\begin{tabular}{|c|c|c|c|}
\hline & $\begin{array}{l}\text { non-SCM } \\
(n=34)\end{array}$ & $\begin{array}{l}\text { SCM } \\
(n=10)\end{array}$ & $\mathbf{P}$ \\
\hline \multicolumn{4}{|l|}{ Maternal age at delivery } \\
\hline Median (Range) & $22.2(17.0-35.8)$ & $24.8(17.0-39.6)$ & 0.65 \\
\hline \multicolumn{4}{|l|}{ Highest Level of Education } \\
\hline No formal schooling & 2 & 0 & 1 \\
\hline Primary school education & 14 & 4 & 1 \\
\hline Secondary school education & 17 & 5 & 1 \\
\hline Tertiary education & 0 & 1 & 0.24 \\
\hline Unknown & 1 & 0 & 1 \\
\hline \multicolumn{4}{|l|}{ Enrollment clinic } \\
\hline Peri-urban & 10 & 4 & 0.72 \\
\hline Rural & 24 & 6 & 1 \\
\hline \multicolumn{4}{|l|}{ Major water source } \\
\hline Borehole/well with hand pump & 2 & 0 & 1 \\
\hline Water carrier/tanker & 1 & 0 & 1 \\
\hline Flowing river or stream & 10 & 1 & 0.42 \\
\hline Piped - internal & 2 & 2 & 0.26 \\
\hline Piped public tap/kiosk & 11 & 4 & 0.71 \\
\hline Piped yard tap & 1 & 2 & 0.15 \\
\hline Rainwater tank & 1 & 0 & 1 \\
\hline Dam or pond & $v_{>}$ & 1 & 1 \\
\hline \multicolumn{4}{|l|}{ Toilet Type } \\
\hline Flush toilet & 2 & 2 & 0.26 \\
\hline None & 14 & 2 & 0.48 \\
\hline Open pit latrine & 15 & 6 & 0.76 \\
\hline Ventilated pit latrine & 3 & 0 & 1 \\
\hline \multicolumn{4}{|l|}{ House Type } \\
\hline Brick & 0 & 2 & 0.06 \\
\hline Cement block & 21 & 7 & 1 \\
\hline Mixed materials (temporary) & 1 & 0 & 1 \\
\hline Mud block & 1 & 0 & 1 \\
\hline Sticks, mud, stone & 11 & 1 & 0.42 \\
\hline \multicolumn{4}{|l|}{ Main Income Provider } \\
\hline Don't know & 1 & 0 & 1 \\
\hline Household member away & 5 & 2 & 0.66 \\
\hline Household member living at home & 26 & 8 & 1 \\
\hline Other (not household member) & 2 & 0 & 1 \\
\hline \multicolumn{4}{|l|}{ Number of previous live born } \\
\hline Median (Range) & $1.0(0-6)$ & $1.0(0-4)$ & 0.32 \\
\hline \multicolumn{4}{|l|}{ Mode of delivery } \\
\hline Caesarian Section & 3 & 2 & 0.58 \\
\hline Vaginal - breech & 1 & 0 & 1 \\
\hline Uncomplicated vaginal delivery & 30 & 8 & 1 \\
\hline
\end{tabular}



samples

\begin{tabular}{|c|c|c|c|c|c|c|c|c|}
\hline & \multirow[t]{2}{*}{ Factor } & \multicolumn{3}{|c|}{ Controls } & \multicolumn{3}{|c|}{ SCM } & \multirow[t]{2}{*}{ P value } \\
\hline & & $\mathrm{n}$ & mean $(\mathrm{SD})$ & median (Q1-Q3) & $\mathrm{n}$ & mean (SD) & median (Q1-Q3) & \\
\hline \multirow{8}{*}{ Th1 cytokines } & IL-2 & 90 & $9,2(2,7)$ & $9,1(7,3-10,8)$ & 18 & $16,6(24,187)$ & $9,2(7,9-14,7)$ & 0.235 \\
\hline & IL-2R & 90 & $67,6(74)$ & $64,2(32,6-84,7)$ & 18 & $292(313,57)$ & $127(70-496)$ & $<.001$ \\
\hline & IL-12p40/70 & 90 & $60,3(32,2)$ & $52,8(39,1-70,2)$ & 18 & $195,5(201,16)$ & $149(56,8-225)$ & $<.001$ \\
\hline & $\mathrm{IL}-15$ & 90 & $67,4(45,3)$ & $58,7(43,7-75,5)$ & 18 & $185,3(219,18)$ & $92,3(42,3-259)$ & $<0.01$ \\
\hline & IFN- $\alpha$ & 90 & $9,7(4,4)$ & $7,5(7,5-7,5)$ & 18 & $22,1(18,015)$ & $20,8(7,5-27,3)$ & $<.001$ \\
\hline & IFN-y & 90 & $38,1(9,7)$ & $38,7(33,2-44,3)$ & 18 & $92,8(81,264)$ & $54,8(40,9-92,5)$ & $<.001$ \\
\hline & MIG & 90 & $137,9(192)$ & $91,6(25,8-148)$ & 18 & $1199,4(1063,838)$ & $822(298-1939)$ & $<.001$ \\
\hline & IP-10 & 90 & $1107,1(960,6)$ & $930(512-1281)$ & 18 & $4279(2862,82)$ & $3906(1327-7394)$ & $<.001$ \\
\hline \multirow{3}{*}{ Th2 cytokines } & IL-4 & 90 & $8,5(2,5)$ & $8,5(7,7-9,4)$ & 18 & $20,3(17,3)$ & $12,8(8,8-23,2)$ & $<.001$ \\
\hline & $\mathrm{IL}-5$ & 90 & $21,9(2,2)$ & $22,1(21,5-22,5)$ & 18 & $24,2(4,1)$ & $22,1(21,7-25,5)$ & 0.056 \\
\hline & IL-13 & 90 & $14,4(1,6)$ & $14,9(13,3-14,9)$ & 18 & $18,7(8,1)$ & $16,01(11,9-21,4)$ & 0.016 \\
\hline Pro- & IL-7 & 90 & $44,3(54,8)$ & $27,7(19,1-45,2)$ & 18 & $104,2(137,3)$ & $77,9(23,6-135,2)$ & 0.023 \\
\hline inflammatory & $\mathrm{IL}-17$ & 90 & $21,1(6,1)$ & $20,9(16,5-23,4)$ & 18 & $38,3(28,3)$ & $26,8(20,1-41,8)$ & 0.01 \\
\hline cytokines & GMCSF & 90 & $31(69)$ & $21,1(20,1-21,6)$ & 18 & $29,4(20,2)$ & $21,7(20,2-27,3)$ & 0.303 \\
\hline \multirow{4}{*}{$\begin{array}{l}\text { Anti- } \\
\text { inflammatory } \\
\text { markers }\end{array}$} & Lactoferrin & 47 & $8,5(11,3)$ & $5,2(1,8-12,6)$ & 10 & $15,5(17,2)$ & $11,6(2,1-20,2)$ & 0.045 \\
\hline & IL-10 & 90 & $14,5(8,7)$ & $13,9(13,9-14,1)$ & 18 & $32(61,1)$ & $14,72(10,1-19,1)$ & 0.069 \\
\hline & EPO & 30 & $31,1(20)$ & $30,5(16,2-39,2)$ & 8 & $41,9(53,2)$ & $24,8(15,9-41,1)$ & 0.606 \\
\hline & IL-1RA & 90 & $1012,2(2923,1)$ & $559(366-890)$ & 18 & $4198,4(5564,6)$ & $1455(415-6033)$ & $<.001$ \\
\hline \multirow{8}{*}{$\begin{array}{l}\text { Inflammatory } \\
\text { markers }\end{array}$} & B2M & 91 & $8,4(1,7)$ & $8,2(7,4-9,5)$ & 19 & $20(13,1)$ & $13,6(8,1-26,8)$ & $<.001$ \\
\hline & PS100A9 & 43 & $7536,7(9021,7)$ & $4102(2235-9930)$ & 11 & $19697,2(14067,3)$ & $23408(6654-26463)$ & 0.021 \\
\hline & TNF- $\alpha$ & 90 & $67,6(582,7)$ & $5,0(5,0-5,0)$ & 18 & $631,3(1357,8)$ & $21,4(5,0-231)$ & $<.001$ \\
\hline & IL-6 & 90 & $49(257,7)$ & $9,9(8,1-15,1)$ & 18 & $897,7(2000,4)$ & $70,4(8,3-392)$ & 0.413 \\
\hline & IL-8 & 90 & $825,9(1063,3)$ & $443(182-1099)$ & 18 & $2962,5(2285,8)$ & $4274(396-5080)$ & $<.001$ \\
\hline & $\mathrm{IL}-1 \beta$ & 90 & $23,7(15,2)$ & $21,4(16,5-28,1)$ & 18 & $114,7(261,6)$ & $28,7(18,9-94,3)$ & $<.001$ \\
\hline & RANTES & 90 & $78,4(77,6)$ & $52,6(39,2-89,2)$ & 18 & $395,3(623,7)$ & $197(52-390)$ & $<.001$ \\
\hline & EOTAXIN & 90 & $8,4(5,8)$ & $6,9(5,4-9,5)$ & 18 & $23,7(45,5)$ & $8,6(5,4-14,5)$ & 0.065 \\
\hline
\end{tabular}

${ }^{a} \mathrm{p}$ value of SCM effect in the mixed model 
Table 2. Relationship between SCM and immunological factors secreted in response to bacterial exposure

\begin{tabular}{|c|c|c|c|}
\hline & $\begin{array}{l}\text { Subclinical mastitis }^{\mathrm{a}} \\
\left(\mathrm{Na}^{+} / \mathrm{K}^{+} \geq 1.0\right)\end{array}$ & $\begin{array}{l}\text { Non-SCM } \\
\left(\mathrm{Na}^{+} / \mathrm{K}^{+}<1.0\right)\end{array}$ & p value \\
\hline sCD14 (ng/ml) & $\begin{array}{l}21821(8814-45652) \\
(n=11)\end{array}$ & $\begin{array}{l}10456(5623-18212) \\
(n=46)\end{array}$ & $p=0.056$ \\
\hline MIP-1 $\alpha(\mathrm{pg} / \mathrm{ml})$ & $\begin{array}{l}95.3(26.2-2308.2) \\
(n=18)\end{array}$ & $\begin{array}{l}20.8(15.7-26.2) \\
(n=90)\end{array}$ & $p<0.001$ \\
\hline MIP-1ß (pg/ml) & $\begin{array}{l}150.5(23.3-1356.5) \\
(n=18)\end{array}$ & $\begin{array}{l}26.8(21.9-42.1) \\
(n=90)\end{array}$ & $p=0.001$ \\
\hline MCP-1 (pg/ml) & $\begin{array}{l}2203.2(270.3-5506.8) \\
(n=18)\end{array}$ & $\begin{array}{l}490.5(239.5-1342.3) \\
(n=90)\end{array}$ & $p=0.086$ \\
\hline LPS binding protein ( $\mathrm{ng} / \mathrm{ml}$ ) & $\begin{array}{l}363.8(84.8-459.6) \\
(n=9)\end{array}$ & $\begin{array}{l}65.3(50.3-143.2) \\
(n=43)\end{array}$ & $p=0.009$ \\
\hline$\alpha$-defensins (pg/ml) & $\begin{array}{l}11704(2186-14487) \\
(n=10)\end{array}$ & $\begin{array}{l}78(78-875) \\
(n=50)\end{array}$ & $p<0.001$ \\
\hline antileukoproteinase 1 (ng/ml) & $\begin{array}{l}86.9(38.3-454.1) \\
(n=9)\end{array}$ & $\begin{array}{l}35.3(19.3-57.6) \\
(n=47)\end{array}$ & $p=0.045$ \\
\hline
\end{tabular}

${ }^{\mathrm{a}}$ median (IQR) 


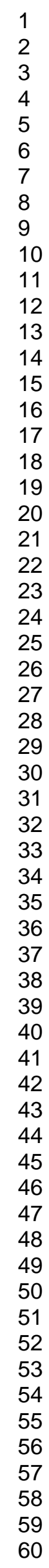

https://mc04.manuscriptcentral.com/prjournal 
A

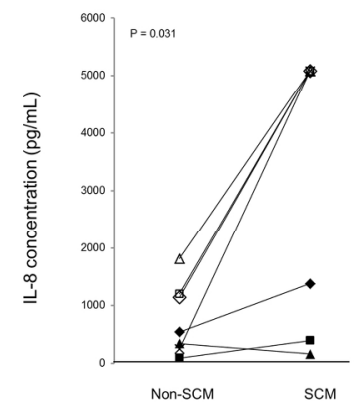

C

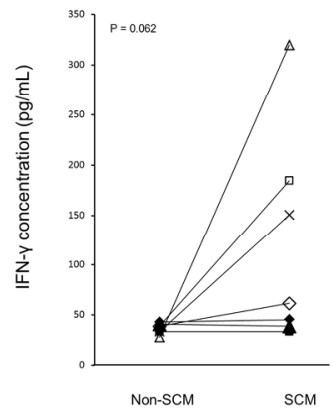

B

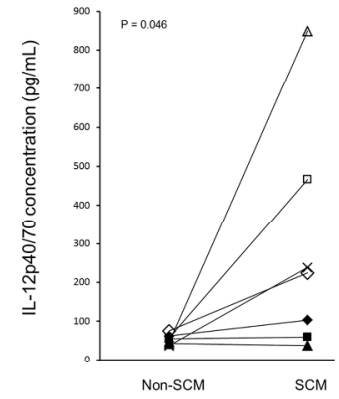

D

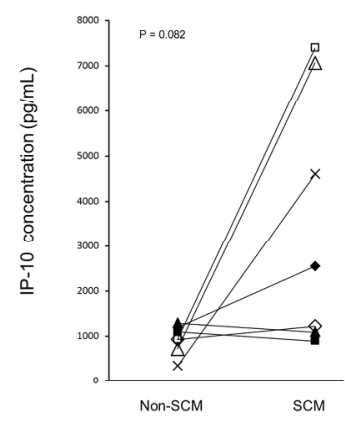

Figure 1 revised

$190 \times 142 \mathrm{~mm}(300 \times 300$ DPI $)$ 
A

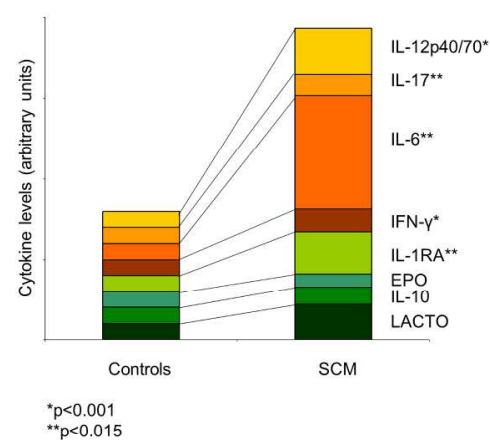

B

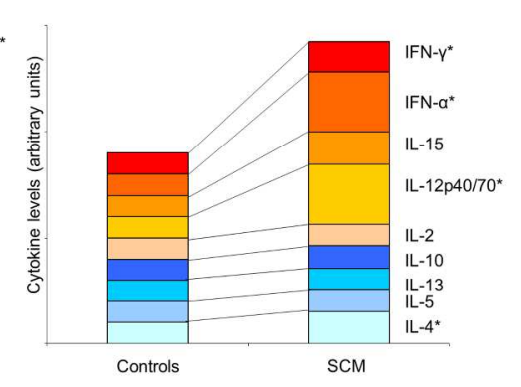

Figure 2 revised $254 \times 338 \mathrm{~mm}(300 \times 300 \mathrm{DPI})$ 


1
2
3
4
5
6
7
8
9
10
11
12
13
14
15
16
17
18
19
20
21
22
23
24
25
26
27
28
29
30
31
32
33
34
35
36
37
38
39
40
41
42
43
44
45
46
47
48
49
50
51
52
53
54
55
56
57
59
60

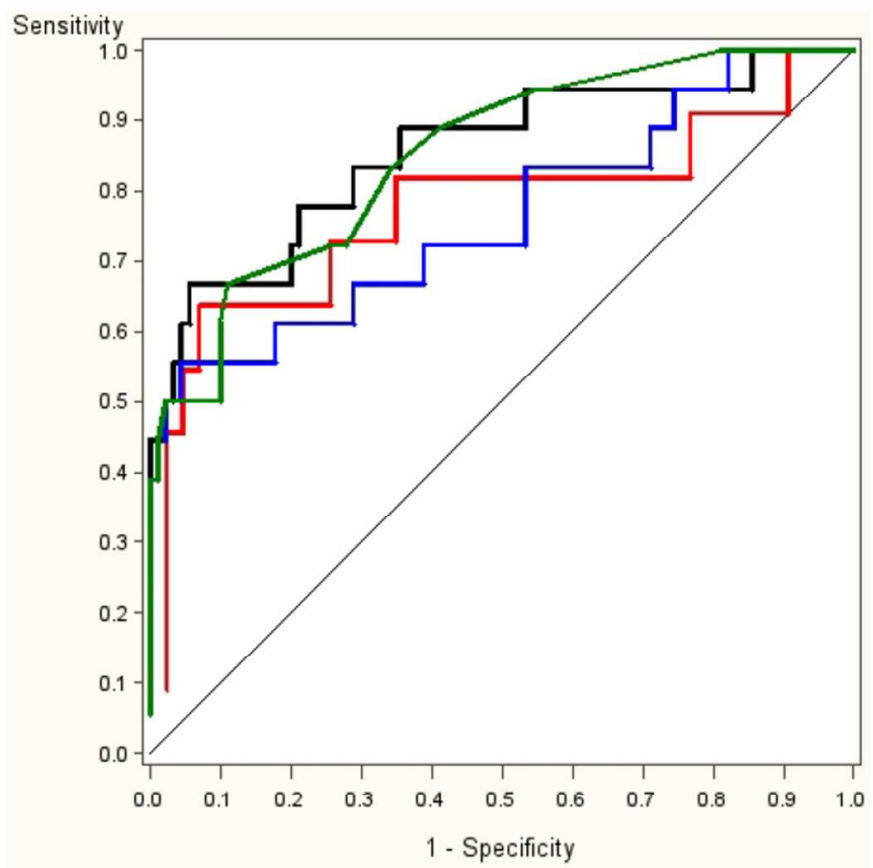

Figure 3 revised

$190 \times 142 \mathrm{~mm}(300 \times 300$ DPI $)$ 